\title{
4 Empirische Ergebnisse
}

\subsection{Einbürgerungen in Wien}

Die stark ansteigenden Zahlen der Einbürgerungen in allen europäischen Einwanderungsländern haben die Staatsbürgerschaft als wichtiges Erhebungskriterium in der amtlichen Statistik zunehmend unbrauchbar werden lassen. In Wien wurden z.B. im Zeitraum 1980 bis 2000 rund 135.000 Ausländer eingebürgert (Antalovsky et al. 2002). Dies hatte zur Folge, dass diese Personen in der amtlichen Statistik nicht mehr greifbar waren. Die Volkszählung 2001 führte daher die Frage nach dem Geburtsland wieder ein.

Migration und Integration sind allerdings keine Prozesse, die mit dem Erhalt des österreichischen Passes abgeschlossen ist (Unterwurzacher 2006: 91). Das Faktum der Einbürgerung repräsentierte in unseren Analysen eine unabhängige Variable, von der angenommen wurde, dass sie die Positionierung von Migranten auf dem Wohnungsmarkt beeinflusst. In der migrationsbezogenen Forschung finden sich hierzu nur wenige Anhaltspunkte, die Staatsbürgerschaft wird zumeist als abhängige Variable untersucht (vgl. die umfangreichen Analysen von Bauböck 2007a, b). Die folgenden empirischen Auswertungen dokumentieren, dass die österreichische Staatsangehörigkeit bei Migranten ein ausgeprägteres Ausmaß an struktureller Integration belegt. Die Akquisition der Staatsangehörigkeit des Aufnahmelandes setzt vielfach auch einen wahrnehmbaren sozioökonomischen Aufstiegsprozess voraus. Dieser manifestiert sich bei den ehemaligen „Gastarbeitern“ besonders deutlich.

Neben der Einbürgerung ist auch die Variable der Aufenthaltsdauer ins Kalkül zu ziehen. Es ist zu fragen, inwieweit Einbürgerung und Aufenthaltsdauer Hand in Hand gehen und welche der beiden Variablen in einem kausalen Bezug zur strukturellen Integration in den Wohnungsmarkt steht.

Die folgenden Dimensionen von Einbürgerung waren für unsere Untersuchung von Relevanz:

- Einbürgerung als ein Schritt zur rechtlichen Gleichstellung,

- Einbürgerung als Endprodukt eines rationalen Entscheidungsprozesses,

- Einbürgerung zum Zwecke einer besseren Arbeits- und Wohnungsmarktpositionierung,

- Einbürgerung als Resultat der Entscheidung für den endgültigen Verbleib im Migrationszielland sowie

- die Nichteinbürgerung als „Leben in zwei Gesellschaften“.

Tabelle 1 gibt einen Überblick über die im Jahr 2005 in Wien erfolgten Einbürgerungen. Von der Gesamtzahl der Einbürgerungen erfolgten rund 29\% durch Verleihung nach freiem Ermessen, 15,4\% wurden auf Basis des Rechtsanspruchs als Ehegatte und das Gros $(38,4 \%)$ in Form der Erstreckung der Staatsbürgerschaft auf Ehegatten oder Kinder durchgeführt. Türken stellten mit 24,4\% die größte ethnonationale Gruppe unter den eingebürgerten Immigranten dar, gefolgt von den Serben mit 20,8\%. 
Ein weiteres zahlenmäßig großes Kontingent stammte aus Bosnien-Herzegowina. Mit deutlichem Abstand folgten Kroaten und Mazedonier. Unter den außereuropäischen Herkunftsländern nahmen Ägypten und Indien die Spitzenpositionen ein. Es ist symptomatisch, dass sich im Jahr 2005 bloß 25 deutsche Staatsbürger einbürgern ließen, denn die Einbürgerung „,rechnet sich“ für Elitemigranten aus der EU am wenigsten.

Tabelle 1: Einbürgerungen in Wien 2005 nach der Herkunft und der rechtlichen Basis

\begin{tabular}{|c|c|c|c|c|c|c|}
\hline \multirow[b]{2}{*}{ Herkunftsland } & \multirow[b]{2}{*}{ insg. } & \multirow[b]{2}{*}{$\begin{array}{r}\text { nach freiem Er- } \\
\text { messen (mind. } \\
10 \text { Jahre } \\
\text { Wohnsitz) }\end{array}$} & \multirow{2}{*}{$\begin{array}{r}\text { Verleihung } \\
\text { Rechtsan- } \\
\text { spruch } \\
\text { Ehegatte }\end{array}$} & \multirow[b]{2}{*}{$\begin{array}{l}\text { sons- } \\
\text { tige }\end{array}$} & \multicolumn{2}{|c|}{ Erstreckung } \\
\hline & & & & & $\begin{array}{l}\text { auf Ehe- } \\
\text { gatten }\end{array}$ & $\begin{array}{r}\text { auf } \\
\text { Kin- } \\
\text { der }\end{array}$ \\
\hline insgesamt abs. & 12.240 & 3.550 & 1.886 & 2.109 & 774 & 3.921 \\
\hline Türkei & 2.981 & 832 & 296 & 388 & 199 & 1.266 \\
\hline Serbien und & 2.550 & 813 & 202 & 673 & 117 & 745 \\
\hline \multicolumn{7}{|l|}{ Montenegro } \\
\hline Bosnien-Herzeg. & 1.597 & 718 & 110 & 110 & 138 & 521 \\
\hline Kroatien & 644 & 253 & 29 & 51 & 53 & 258 \\
\hline Mazedonien & 541 & 199 & 51 & 63 & 18 & 210 \\
\hline Ägypten & 314 & 56 & 130 & 39 & 6 & 83 \\
\hline Indien & 298 & 33 & 100 & 89 & 9 & 67 \\
\hline Polen & 294 & 86 & 56 & 45 & 21 & 86 \\
\hline Deutschland & 23 & 2 & 6 & 10 & 0 & 5 \\
\hline sonstige & 2.998 & 558 & 906 & 641 & 213 & 680 \\
\hline insgesamt in \% & 100,0 & 29,0 & 15,4 & 17,2 & 6,3 & 32,0 \\
\hline Türkei & 100,0 & 27,9 & 9,9 & 13,0 & 6,7 & 42,5 \\
\hline Serbien und & 100,0 & 31,9 & 7,9 & 26,4 & 4,6 & 29,2 \\
\hline \multicolumn{7}{|l|}{ Montenegro } \\
\hline Bosnien-Herzeg. & 100,0 & 45,0 & 6,9 & 6,9 & 8,6 & 32,6 \\
\hline Kroatien & 100,0 & 39,3 & 4,5 & 7,9 & 8,2 & 40,1 \\
\hline Mazedonien & 100,0 & 36,8 & 9,4 & 11,6 & 3,3 & 38,8 \\
\hline Ägypten & 100,0 & 17,8 & 41,4 & 12,4 & 1,9 & 26,4 \\
\hline Indien & 100,0 & 11,1 & 33,6 & 29,9 & 3,0 & 22,5 \\
\hline Polen & 100,0 & 29,3 & 19,0 & 15,3 & 7,1 & 29,3 \\
\hline Deutschland & 100,0 & 8,7 & 26,1 & 43,5 & 0,0 & 21,7 \\
\hline sonstige & 100,0 & 18,6 & 30,2 & 21,4 & 7,1 & 22,7 \\
\hline
\end{tabular}

Quelle: Statistik Austria, eigene Berechnungen. 
Es weisen also vor allem jene Zuwanderergruppen die ausgeprägteste Einbürgerungsneigung auf, die am ehesten vom Wechsel der Staatsbürgerschaft profitieren, die in größerer Zahl in Wien ansässig sind und die sich bereits länger im Land aufhalten. Migranten aus der EU und aus Osteuropa streben in einem geringeren Ausmaß die österreichische Staatsbürgerschaft an als die ehemaligen „Gastarbeiter“. Hierbei spielt die im Durchschnitt längere Aufenthaltsdauer der Letztgenannten ebenso eine Rolle wie deren auf Dauer ausgerichtete Aufenthaltsperspektive. Das Migrationsmuster der transnationalen Mobilität tritt besonders häufig in der Gruppe der Ost-West-Migranten auf und macht eine Einbürgerung wenig profitabel.

In Bezug auf die rechtliche Basis der Einbürgerungen lassen sich ebenfalls gruppenspezifische Divergenzen konstatieren. Die höchsten Anteile der Verleihung nach freiem Ermessen waren in den Herkunftsgruppen aus Bosnien-Herzegowina, Kroatien und Mazedonien zu finden. Die geringsten Anteile fanden sich unter ehemaligen deutschen Staatsbürgern, Indern und Ägyptern. Mehr als 41\% der Einbürgerungen von ägyptischen Staatsangehörigen erfolgten auf der Basis der Verleihung durch den Rechtsanspruch als Ehegatte. In den Herkunftsgruppen aus dem ehemaligen Jugoslawien und unter Bürgern der Türkei war dieser Rechtsttitel von untergeordneter Bedeutung.

Die Einbürgerung infolge der Erstreckung der österreichischen Staatsangehörigkeit auf Kinder war in allen angeführten Gruppen von erheblicher Wichtigkeit. Diese Variante der Einbürgerung trat unter Türken, Kroaten und Mazedoniern am häufigsten auf. Am seltensten erfolgte eine solche Erstreckung auf Kinder mit deutscher Staatsangehörigkeit.

Tabelle 2 beinhaltet eine Zeitreihe der Entwicklung der Einbürgerungen für die mehr als zweieinhalb Dekaden von 1980 bis 2007. In summa sind in Österreich in diesem Zeitraum 497.811 Einbürgerungen erfolgt, wobei mit 45.112 die höchste Zahl im Jahr 2003 erreicht wurde. Im Dezennium zwischen 1980 und 1990 pendelte die jährliche Zahl der Einbürgerungen bei Werten zwischen 7.700 (1982) und knapp 11.000 (1983) Personen. Ab 1991 stiegen die Einbürgerungszahlen kontinuierlich an, um 1999 bereits die Schwelle von 25.000 zu überschreiten. Nach der Jahrtausendwende setzte sich der progressive Trend in verstärktem Maß fort, um 2003 seinen bisherigen Kulminationspunkt zu erreichen. Diese Entwicklung hing sowohl mit der steigenden Zahl von Zuwanderern insgesamt als auch mit deren längerer Aufenthaltsdauer zusammen, sodass die Zahl der einbürgerungsberechtigten Immigranten stetig anstieg. Danach kam es zu einem drastischen Einbruch der Einbürgerungszahlen. Im Jahr 2005 fanden um fast 10.000 Einbürgerungen weniger statt als noch 2003. 2006 und 2007 waren durch weitere ausgeprägte Rückgänge gekennzeichnet. Bezogen auf das jeweils vorhergehende Jahr zeigen die Einbürgerungszahlen erhebliche Variationen. Jahre mit Zuwächsen wechselten mit solchen ab, in denen erhebliche Rückgänge zu verzeichnen waren. Der höchste Zuwachs wurde 1983 erreicht, weitere starke Anstiege manifestierten sich auch 1999 sowie 2001. Der krasseste bundesweite Rückgang (-46,5\%) betraf 2007. 
Tabelle 2: Einbürgerungen in Österreich und Wien 1980-2007

\begin{tabular}{|c|c|c|c|c|c|}
\hline & $\begin{array}{r}\text { Öster- } \\
\text { reich }\end{array}$ & $\begin{array}{r}\text { Veränderung } \\
\text { gegenüber dem } \\
\text { Vorjahr }\end{array}$ & Wien & $\begin{array}{r}\text { Veränderung } \\
\text { gegenüber dem } \\
\text { Vorjahr }\end{array}$ & $\begin{array}{l}\text { Wien- } \\
\text { anteil in \% }\end{array}$ \\
\hline 1980 & 8.602 & - & 3.996 & - & 46,5 \\
\hline 1981 & 7.980 & $-7,2$ & 3.579 & $-10,4$ & 44,8 \\
\hline 1982 & 7.752 & $-2,9$ & 3.239 & $-9,5$ & 41,8 \\
\hline 1983 & 10.904 & 40,7 & 4.843 & 49,5 & 44,4 \\
\hline 1984 & 8.876 & $-18,6$ & 3.533 & $-27,0$ & 39,8 \\
\hline 1985 & 8.491 & $-4,3$ & 3.546 & 0,4 & 41,8 \\
\hline 1986 & 10.015 & 17,9 & 4.178 & 17,8 & 41,7 \\
\hline 1987 & 8.114 & $-19,0$ & 3.646 & $-12,7$ & 44,9 \\
\hline 1988 & 8.233 & 1,5 & 4.111 & 12,8 & 49,9 \\
\hline 1989 & 8.470 & 2,9 & 4.580 & 11,4 & 54,1 \\
\hline 1990 & 9.199 & 8,6 & 6.312 & 37,8 & 68,6 \\
\hline 1991 & 11.394 & 23,9 & 8.047 & 27,5 & 70,6 \\
\hline 1992 & 11.920 & 4,6 & 7.898 & $-1,9$ & 66,3 \\
\hline 1993 & 14.402 & 20,8 & 8.671 & 9,8 & 60,2 \\
\hline 1994 & 16.270 & 13,0 & 9.261 & 6,8 & 56,9 \\
\hline 1995 & 15.309 & $-5,9$ & 6.841 & $-26,1$ & 44,7 \\
\hline 1996 & 16.243 & 6,1 & 9.044 & 32,2 & 55,7 \\
\hline 1997 & 16.274 & 0,2 & 8.628 & $-4,6$ & 53,0 \\
\hline 1998 & 18.321 & 12,6 & 9.350 & 8,4 & 51,0 \\
\hline 1999 & 25.032 & 36,6 & 11.007 & 17,7 & 44,0 \\
\hline 2000 & 24.645 & $-1,5$ & 9.469 & $-14,0$ & 38,4 \\
\hline 2001 & 32.080 & 30,2 & 13.394 & 41,5 & 41,8 \\
\hline 2002 & 36.282 & 13,1 & 14.672 & 9,5 & 40,4 \\
\hline 2003 & 45.112 & 24,3 & 18.085 & 23,3 & 40,1 \\
\hline 2004 & 42.174 & $-6,5$ & 16.354 & $-9,6$ & 38,8 \\
\hline 2005 & 35.417 & $-16,0$ & 12.240 & $-25,2$ & 34,6 \\
\hline 2006 & 26.259 & $-25,9$ & 8.654 & $-29,3$ & 32,9 \\
\hline 2007 & 14.041 & $-46,5$ & 5.200 & $-39,9$ & 37,0 \\
\hline $\begin{array}{l}\text { Summe } \\
\text { 1980-2007 }\end{array}$ & 497.811 & & 222.378 & & 44,7 \\
\hline
\end{tabular}

Quelle: Statistik Austria, eigene Berechnungen.

Für Wien sind ähnliche, teils aber von der Entwicklung auf Bundesebene deutlich abweichende Trends festzustellen (vgl. Tabelle 2). Mit 222.378 Einbürgerungen im Analysezeitraum betrug der Anteil Wiens an allen bundesweiten Einbürgerungen nahezu 45\%. Der Wienanteil weist eine beträchtliche jährliche Schwankungsbreite 
auf. Die höchsten Anteile Wiens an allen österreichweiten Einbürgerungen sind für 1990-1992 ausgewiesen. Mit nur 32,9\% aller Einbürgerungen des jeweiligen Jahres wies Wien im Jahr 2006 den niedrigsten Anteil an allen Einbürgerungen innerhalb des Untersuchungszeitraumes auf. Die höchste Absolutzahl war - dem Bundestrend entsprechend - für 2003 ausgewiesen, die niedrigste für 1982. In den 1980er Jahren wechselten einander Jahre mit Zuwächsen sowie solche mit Rückgängen ab. Der Spitzenzuwachs manifestierte sich 1983 mit einem Plus von 49,5\% gegenüber dem Vorjahr. Hohe Anstiege sind für 1990 und 2001 ausgewiesen. Die krassesten Rückgänge betrafen die Jahre 2006 (-29,3\%) und 2007 (-39,9\%). Der Anteil der Bundeshauptstadt an allen Einbürgerungen hat sich nach Rückgängen seit 2002 im Jahre 2007 wieder um vier Prozentpunkte erhöht.

Tabelle 3: Einbürgerungsraten in Wien nach den wichtigsten Herkunftsländern 2005

\begin{tabular}{lrrrr}
\hline & $\begin{array}{r}\text { Wohn- } \\
\text { bevölkerung }\end{array}$ & $\begin{array}{r}\text { Einbürge- } \\
\text { rungen abs. }\end{array}$ & $\begin{array}{r}\text { Einbürge- } \\
\text { rungsrate }\end{array}$ & $\begin{array}{r}\text { Einbürge- } \\
\text { rungen in \% }\end{array}$ \\
\hline insgesamt & $\mathbf{3 0 9 . 1 8 4}$ & $\mathbf{1 2 . 2 4 0}$ & $\mathbf{4 , 0}$ & $\mathbf{1 0 0 , 0}$ \\
Serbien u. Montenegro & 76.666 & 2.550 & 3,3 & 20,8 \\
Türkei & 39.901 & 2.981 & 7,5 & 24,4 \\
Polen & 21.610 & 294 & 1,4 & 2,4 \\
Deutschland & 20.417 & 23 & 0,1 & 0,2 \\
Bosnien-Herzegowina & 17.805 & 1.597 & 9,4 & 13,0 \\
Kroatien & 16.915 & 644 & 3,8 & 5,3 \\
Rumänien & 7.796 & 261 & 3,3 & 2,1 \\
Mazedonien & 7.340 & 541 & 7,4 & 4,4 \\
Slowakei & 6.360 & 107 & 1,7 & 0,9 \\
VR China & 5.557 & 151 & 2,7 & 1,2 \\
Ungarn & 5.271 & 46 & 0,9 & 0,4 \\
Russland & 4.741 & 119 & 2,5 & 1,0 \\
Indien & 4.615 & 298 & 6,5 & 2,4 \\
Iran & 4.026 & 252 & 6,3 & 2,1 \\
Ägypten & 3.240 & 314 & 9,7 & 2,6 \\
sonstige & 66.924 & 2.062 & 3,1 & 16,8 \\
\hline
\end{tabular}

Quelle: Statistik Austria, eigene Berechnungen.

Tabelle 3 dokumentiert eine Differenzierung der Einbürgerungen nach der ethnonationalen Herkunft sowie nach Einbürgerungsraten und Anteilen der unterschiedlichen Herkunftsgruppen. Die größte Gruppe mit ausländischer Staatsbürgerschaft stellt nach wie vor die Community aus Serbien und Montenegro dar, gefolgt von den türkischen Staatsbürgern. Die Analyse auf der Basis der Einbürgerungszahlen weist für das Jahr 2005 die Türken als jene Herkunftsgruppe aus, die die höchste Zahl an Einbürge- 
rungen vornehmen haben lassen. Die mehr als doppelt so große Community der Serben liegt an der zweiten Stelle, mit deutlichem Abstand gefolgt von den Migranten aus Bosnien-Herzegowina.

Bezieht man die Einbürgerungszahlen auf den Stock der jeweiligen Ethnic Communities, so wurde die höchste Naturalisationsrate mit 9,7\% von den Ägyptern erreicht. Unter den großen Herkunftsgruppen wiesen die Migranten aus BosnienHerzegowina mit 9,4\% im Jahr 2005 die höchste Rate an Naturalisationen auf. An zweiter Stelle lag die türkische Herkunftsgruppe ex aequo mit den mazedonischen Staatsbürgern. Auch unter Immigranten aus Indien und dem Iran manifestierte sich eine beträchtliche Einbürgerungsneigung. Schwach ausgeprägt ist die Tendenz zur Annahme der österreichischen Staatsbürgerschaft unter den Deutschen sowie bei den Ungarn. Auch Slowaken und Polen sind nur selten zu einem Wechsel der Staatsbürgerschaft bereit.

Zieht man die Gesamtzahl der 2005 erfolgten Naturalisationen als Bezugsgröße heran, so entfielen die höchsten prozentuellen Anteile auf ehemalige türkische Staatsbürger sowie Bürger Serbien-Montenegros und Bosnien-Herzegowinas. 58\% aller Einbürgerungen betrafen also Bürger von nur drei Herkunftsländern.

Tabelle 4: Einbürgerungen in Wien 2005 nach Alter und Geschlecht

\begin{tabular}{lrrrrrr}
\hline & unter 18 & 18 bis 29 & 30 bis 44 & 45 bis 59 & 60 und mehr & insgesamt \\
\hline insg. abs. & 4.690 & 2.031 & 3.729 & 1.493 & 297 & 12.240 \\
Männer & 2.407 & 977 & 1.824 & 774 & 139 & 6.121 \\
Frauen & 2.283 & 1.054 & 1.905 & 719 & 158 & 6.119 \\
insg. in \% & 38,3 & 16,6 & 30,5 & 12,2 & 2,4 & 100,0 \\
Männer & 39,3 & 16,0 & 29,8 & 12,6 & 2,3 & 100,0 \\
Frauen & 37,3 & 17,2 & 31,1 & 11,8 & 2,6 & 100,0 \\
\hline
\end{tabular}

Quelle: Statistik Austria, eigene Berechnungen.

Die Einbürgerungsneigung variiert auch in Abhängigkeit von soziodemographischen Variablen. Für die im Jahr 2005 in der Bundeshauptstadt erfolgten Naturalisationen ist eine weitgehend ausgewogene Geschlechterrelation in allen Altersgruppen festzustellen. Es manifestieren sich aber zwei altersmäßige Schwerpunkte: Kinder und Jugendliche im Alter bis 18 Jahren sowie Personen im mittleren Lebensalter. Über 60Jährige lassen sich nur mehr in den seltensten Fällen auf einen Wechsel der Staatsangehörigkeit ein. Ein interessantes Faktum stellt auch die schwache Präsenz der jungen Erwachsenen im Alter von 18 bis 29 Jahren dar (vgl. Tabelle 4).

Tabelle 5 beinhaltet eine Aufschlüsselung der Naturalisationen des Jahres 2005 nach dem Familienstand. Die Hälfte der Eingebürgerten war ledig, was auch damit zusammenhängt, dass die Gruppe der unter 18-Jährigen (vgl. oben) unter den Eingebürgerten am stärksten vertreten war. Fast $45 \%$ waren verheiratet. Gering war der 
Anteil der Geschiedenen. Die Wiener Daten weisen auf bloß geringe Unterschiede nach Familienstand und Geschlechtszugehörigkeit hin, allerdings treten entsprechende Variationen eher auf der Ebene der einzelnen Migrantengruppen hervor.

Tabelle 5: Einbürgerungen in Wien 2005 nach Geschlecht und Familienstand

\begin{tabular}{lrrrrr}
\hline & ledig & verheiratet & verwitwet & geschieden & insgesamt \\
\hline insgesamt abs. & 6.129 & 5.489 & 135 & 487 & 12.240 \\
Männer & 3.209 & 2.676 & 24 & 212 & 6.121 \\
Frauen & 2.920 & 2.813 & 111 & 275 & 6.119 \\
insgesamt in \% & 50,1 & 44,8 & 1,1 & 4,0 & 100,0 \\
Männer & 52,4 & 43,7 & 0,4 & 3,5 & 100,0 \\
Frauen & 47,7 & 46,0 & 1,8 & 4,5 & 100,0 \\
\hline
\end{tabular}

Quelle: Statistik Austria, eigene Berechnungen.

\subsection{Herkunftsgruppenbezogene Analysen}

Die Volkszählungsdaten ermöglichen keinerlei Rückschlüsse auf die Aufenthaltsdauer oder eine etwaige Einbürgerung von Migranten, sondern beinhalten lediglich die Staatsbürgerschaft und das Geburtsland. Anhand dieser beiden Variablen ist es empirisch näherungsweise möglich, die Wohnbevölkerung mit Migrationshintergrund in drei Gruppen zu untergliedern: ${ }^{5}$

1. ausländische Staatsbürger mit Geburtsort im Ausland, d.h. Zuwanderer im eigentlichen Sinn,

2. ausländische Staatsbürger mit Geburtsort in Österreich, d.h. mehrheitlich Angehörige der zweiten oder dritten Generation, und

3. österreichische Staatsbürger mit Geburtsland im Ausland (Eingebürgerte).

In der Volkszählung 2001 wurde für die Bundeshauptstadt Wien eine Gesamtbevölkerung von 1.550.123 Personen erhoben. 74,1\% davon wurden in Österreich geboren und besitzen eine österreichische Staatsbürgerschaft. Es ist wahrscheinlich, dass einige Angehörige dieser Gruppe auch der zweiten Generation zuzurechnen sind, die bereits die österreichische Staatsbürgerschaft besitzt. Um wie viele Personen es sich dabei handelt, ist statistisch nicht herauszufiltern.

5 Es ist nicht möglich, Sonderfälle statistisch zu eruieren. Mittlerweile eingebürgerte, in Wien geborene Personen (= zweite Generation) können nicht herausgefiltert werden, da beide Dimensionen in der Volkszählung der Kategorie „Österreich“ hinzuzurechnen sind. Man kann aber davon ausgehen, dass die große Mehrheit der Wohnbevölkerung einer dieser Gruppen zuzurechnen ist. 
Tabelle 6: Bevölkerung in Wien nach vorhandenem/nicht vorhandenem Migrationshintergrund 2001

\begin{tabular}{|c|c|c|c|c|}
\hline Kategorie & Staatsbürgerschaft & Geburtsland & abs. & in $\%$ \\
\hline Inländer ohne Migrationshintergrund & Österreich & Österreich & 1.149 .270 & 74,1 \\
\hline Ausländer & Ausland & Ausland & 213.700 & 13,8 \\
\hline Neoösterreicher & Österreich & Ausland & 152.589 & 9,8 \\
\hline Zweite Generation & Ausland & Österreich & 34.564 & 2,2 \\
\hline insgesamt & & & 1.550 .123 & 100,0 \\
\hline
\end{tabular}

Quelle: Volkszählung 2001, eigene Berechnungen.

Laut Tabelle 6 war mehr als ein Viertel der Wiener Bevölkerung mit Migration innerhalb der Familie konfrontiert. 13,8\% sind Ausländer, die selbst zuwanderten, fast $10 \%$ wurden im Ausland geboren, besitzen aber die österreichische Staatsbürgerschaft und 34.564 Personen wurden bis dato nicht eingebürgert.

Es stellt sich die Frage, ob sich zwischen verschiedenen Herkunftsgruppen Unterschiede der „Einbürgerungsneigung“ feststellen lassen. Wie vielschichtig das Phänomen der Migration in der Realität tatsächlich ist, zeigt sich darin, dass auch eine Restkategorie zu berücksichtigen ist: So kann eine Person kroatischer Staatsbürger sein, wurde aber in einem anderen Land als in Kroatien oder in Österreich geboren. Umgekehrt besteht die Möglichkeit, dass eine Person zwar in Kroatien geboren wurde und zum Volkszählungszeitpunkt in Österreich lebte, aber dennoch eine andere Staatsbürgerschaft besitzt.

Tabelle 7 veranschaulicht die nach den größten ethnonationalen Gruppen differenzierten Relationen zwischen den Eingebürgerten und Nichteingebürgerten sowie der zweiten Generation. Auch die quantitativ kleineren Gruppen der jeweiligen Staatsbürger mit einem anderen Geburtsland sowie der in einem Land Geborenen mit einer anderen Staatsbürgerschaft sind ausgewiesen. Herangezogen werden die größten Herkunftsgruppen, die anderen sind zu klein, um sie nach dem Kriterium des Migrationshintergrundes aufgliedern zu können. Immerhin machen die angegebenen Länder $72 \%$ aller ausländischen Staatsbürger und $61 \%$ aller im Ausland geborenen Personen in Wien aus. ${ }^{6}$

Das wichtigste Herkunftsland ist mit 86.777 Personen Serbien und Montenegro ${ }^{7}$. Trotz der teilweise schon sehr langen Aufenthaltsdauer (seit dem Beginn der Gastarbeiterzuwanderung) vieler Angehöriger dieser Herkunftsgruppe ist nur rund ein Fünftel der Serben eingebürgert worden. Die Mehrheit besitzt Ausländerstatus und demzufolge ist auch der Anteil der zweiten Generation mit serbischer Staatsbürgerschaft relativ hoch.

6 Die Herkunftsgruppe „Tschechien“ besteht in der Mehrzahl aus Volksdeutschen.

7 Die Abspaltung Montenegros von Serbien besaß 2001 noch keine Relevanz. 
Tabelle 7: Migranten aus den wichtigsten Herkunftsländern in Wien 2001

\begin{tabular}{lrrrrrr}
\hline & $\begin{array}{r}\text { Einge- } \\
\text { bürgerte }\end{array}$ & $\begin{array}{r}\text { Aus- } \\
\text { länder }\end{array}$ & $\begin{array}{r}\text { 2. Ge- } \\
\text { neration }\end{array}$ & $\begin{array}{r}\text { SB ..., in ... geboren, } \\
\text { anderes GL } \\
\text { andere SB }\end{array}$ & $\begin{array}{r}\text { insg. } \\
\text { abs. }\end{array}$ \\
\hline Serbien und & 19,1 & 63,4 & 13,6 & 2,2 & 1,7 & 86.777 \\
Montenegro & & & & & & \\
Türkei & 30,1 & 53,7 & 15,3 & 0,5 & 0,3 & 56.255 \\
Bosnien- & 20,9 & 46,9 & 7,5 & 2,3 & 22,3 & 38.124 \\
Herzegowina & & & & & & \\
Deutschland & 53,4 & 34,4 & 4,5 & 5,1 & 2,7 & 28.996 \\
Polen & 46,2 & 47,7 & 4,3 & 0,3 & 1,5 & 26.116 \\
Kroatien & 21,4 & 25,6 & 14,1 & 35,8 & 3,1 & 21.491 \\
Mazedonien & 18,7 & 64,6 & 11,0 & 2,4 & 3,2 & 7.666 \\
Tschechien & 88,1 & 9,2 & 0,4 & 0,3 & 2,0 & 21.310 \\
Ungarn & 63,4 & 31,7 & 1,2 & 1,0 & 2,7 & 12.193 \\
Rumänien & 58,1 & 34,2 & 3,8 & 0,3 & 3,6 & 9.694 \\
Iran & 46,9 & 47,7 & 1,1 & 0,6 & 3,8 & 7.778 \\
Slowakei & 55,1 & 39,5 & 1,7 & 1,4 & 2,2 & 7.771 \\
Indien & 39,2 & 53,2 & 5,8 & 0,5 & 1,4 & 6.054 \\
Ägypten & 51,0 & 43,8 & 3,4 & 0,3 & 1,5 & 5.878 \\
Italien & 32,2 & 53,5 & 6,7 & 5,5 & 2,0 & 4.452 \\
China & 36,9 & 52,3 & 6,5 & 2,0 & 2,3 & 4.276 \\
Slowenien & 62,6 & 24,6 & 2,9 & 3,6 & 6,3 & 2.651 \\
\hline
\end{tabular}

Quellen: Sonderauswertung MA 66, Volkszählung 2001; eigene Berechnungen.

Ein recht ähnliches Verteilungsbild trifft auf die zweitgrößte Immigrantengruppe, die Türken, zu. Der Anteil der Eingebürgerten ist unter diesen mit 30\% zwar höher als bei den Serben, aber noch wurden fast drei Viertel der türkischen Migranten nicht eingebürgert. Der Anteil der zweiten Generation liegt mit 15,3\% über dem bei den Serben. Mehr als ein Fünftel der Migranten aus Bosnien wurde zwar in Bosnien geboren, besaß aber eine andere Staatsbügerschaft als die bosnische. Ein weiteres rundes Fünftel hat sich einbürgern lassen. Mit rund $47 \%$ ist die Präsenz der Nichteingebürgerten deutlich geringer als bei den Serben und liegt auch unter dem Wert in der türkischen Herkunftsgruppe. Hoch (etwa 36\%) ist unter den Kroaten der Anteil jener mit kroatischer Staatsbürgerschaft, aber einem Geburtsort außerhalb Kroatiens. Nicht eingebürgert waren 2001 fast 40\% der Kroaten. In der kleineren Gruppe der Mazedonier haben sich mehr als drei Viertel noch nicht einbürgern lassen.

Unter den großen Migrantengruppen nehmen die 29.000 Deutschen mit 53,4\% die Spitzenposition hinsichtlich der Einbürgerungsneigung ein. Allerdings handelt es sich bei der Majorität der eingebürgerten Deutschen nicht um Migranten (deren Einbürgerungsneigung ist sehr gering!), sondern um frühere Zuwanderungswellen. Etwas ge- 
ringer ist die Einbürgerungsneigung der polnischen Community. Die bereits lange in Österreich Ansässigen haben sich in hohem Ausmaß einbürgern lassen.

Bei den kleineren Migrantengruppen zeigen sich beträchtliche Variationen der Anteile eingebürgerter Personen. Spitzenwerte entfallen auf Tschechen und Ungarn. Hohe Anteile an Naturalisierten finden sich auch in der rumänischen sowie in der slowakischen Herkunftsgruppe. Weiters manifestiert sich vor allem bei den Ägyptern, in der indischen und in der chinesischen Community eine hohe Einbürgerungsneigung.

\subsection{Raumbezogene Analysen}

\subsubsection{Ethnische Konzentration und Segregation im Spiegel der Einbürgerung}

Im Hinblick auf die räumliche Integration nach dem Kriterium der Einbürgerung führt eine komparative Analyse der Konzentrationsindizes zu aufschlussreichen Resultaten. Tabelle 8 enthält die Konzentrationsindizes ${ }^{8}$ für die zahlenmäßig größten Zuwanderergruppen in Wien, und zwar jeweils aufgeschlüsselt nach den Subkategorien von Eingebürgerten, Ausländern und Angehörigen der zweiten Generation.

Tabelle 8: Konzentrationsindizes auf der Ebene der Zählsprengel 2001

\begin{tabular}{lrrrr}
\hline & Eingebürgerte & Ausländer & zweite Generation & \\
\hline Serbien und Montenegro & 35,2 & 43,8 & 48,2 & \\
Türkei & 45,7 & 51,2 & 55,5 & \\
Bosnien-Herzegowina & 40,3 & 47,6 & 57,4 & \\
Deutschland & 29,3 & 33,5 & 51,8 & \\
Polen & 37,1 & 44,8 & 63,9 & \\
Kroatien & 37,6 & 45,1 & 56,6 & \\
Österreicher ohne MH & & & & 28,4 \\
\hline
\end{tabular}

Quellen: Sonderauswertung MA 66, Volkszählung 2001; eigene Berechnungen.

$\mathrm{Zu}$ Vergleichszwecken ist auch der Wert für Österreicher ohne Migrationshintergrund angegeben, denn auch die Inländer leben nicht räumlich gleichmäßig über das Stadtgebiet verteilt. Die Indexwerte zeigen eine beträchtliche Variationsbreite, dennoch tritt auch ein einheitlicher Trend hervor: Die Eingebürgerten wohnen am wenigsten konzentriert. Die „Ausländer“ weisen mittelstarke Konzentrationsindizes auf. Das höchste Konzentrationsrating erreicht Polen, gefolgt von Bosnien-Herzego-

8 Der Konzentrationsindex gibt an, wieviel Prozent der Bevölkerung des gesamten Untersuchungsgebiets umverteilt werden müssten, um eine Gleichverteilung in allen Teilräumen zu erreichen. Der Index sagt jedoch nichts darüber aus, wer in welchen Teilen der Stadt lebt. 
wina. Am schwächsten konzentriert sich die zweite Generation der Serben und Montenegriner. Bei den Eingebürgerten erreicht die Konzentration der Österreicher türkischer und bosnischer Herkunft die höchsten Werte. Die schwächste Konzentrationstendenz manifestiert sich unter eingebürgerten Deutschen. Unter den ausländischen Staatsbürgern konzentrieren sich Bürger der Türkei sowie Bosnien-Herzegowinas am stärksten.

Der Dissimilaritätsindex lässt Rückschlüsse darauf zu, wer in wessen Nähe wohnt bzw. welche Gruppen distanziert voneinander anzutreffen sind. Im Folgenden wird der Frage nachgegangen, wie sich die großen Immigrantengruppen in der Stadt verteilen (vgl. Tabelle 9).

\section{Tabelle 9: Dissimilaritätsindizes auf der Ebene der Zählsprengel - Vergleich nach} Herkunftsländern und Subgruppen 2001

\begin{tabular}{lrrr}
\hline & $\begin{array}{r}\text { Eingebürgerte/ } \\
\text { Ausländer }\end{array}$ & $\begin{array}{r}\text { Eingebürgerte/ } \\
\text { 2. Generation }\end{array}$ & $\begin{array}{r}\text { Ausländer/ } \\
\text { 2. Generation }\end{array}$ \\
\hline Serbien und Montenegro & 33,2 & 37,1 & 15,8 \\
Türkei & 32,5 & 38,9 & 17,3 \\
Bosnien-Herzegowina & 35,6 & 43,1 & 27,1 \\
Deutschland & 27,9 & 47,8 & 43,3 \\
Polen & 37,4 & 54,4 & 42,7 \\
Kroatien & 39,7 & 50,3 & 26,5 \\
\hline
\end{tabular}

Quellen: Sonderauswertung MA 66, Volkszählung 2001; eigene Berechnungen.

Beim Vergleich der Eingebürgerten mit den Ausländern weisen die Kroaten den höchsten Dissimilaritätsindex auf, gefolgt von den Polen. Also stehen einander in diesen beiden Gruppen Eingebürgerte und Nichteingebürgerte räumlich am distanziertesten gegenüber. Die Einbürgerung ist somit für diese beiden Gruppen als eine Determinante räumlicher Mobilität belegt. Schwächer ist die räumliche Dissimilarität zwischen den Eingebürgerten und den Nichteingebürgerten unter Bosniern, Serben und Türken ausgeprägt. Am wenigsten distanziert voneinander anzutreffen sind eingebürgerte und nichteingebürgerte Deutsche. Durchwegs hohe Indexwerte werden bei der Analyse Eingebürgerte versus zweite Generation erreicht. Hierbei ist die Distanz unter Polen und Kroaten am ausgeprägtesten, bei Serben am schwächsten.

Die Vergleichsanalyse von Ausländern versus zweite Generation lässt auf eine schwächere Distanzierung dieser beiden Kategorien schließen. Die niedrigsten Indexwerte liegen für Serbien-Montenegro und die Türkei vor. Am stärksten sondern sich die Wohngebiete der Ausländer und der zweiten Generation im Fall der Polen und der Deutschen voneinander.

Bezogen auf die österreichische Wohnbevölkerung (vgl. Tabelle 10) wird deutlich, dass die zweite Generation gegenüber den Österreichern am distanziertesten verteilt ist - dies gilt für alle ethnonationalen Gruppen. Am geringsten ist die Wohndistanz 
der zweiten Generation der Deutschen der österreichischen Bevölkerung gegenüber. Ähnliche Indexwerte sind für die zweite Generation der Türken, der Kroaten und der Bosnier festzustellen. Das stärkste Ausmaß an Wohndistanz manifestiert sich zwischen Polen und Österreichern. Die Dissimilaritätsindizes der Ausländer versus Österreicher weisen auf eine geringere Wohndistanz hin als im Fall der zweiten Generation. Am stärksten fallen die Wohngebiete der Türken und jene der Inländer auseinander. Die Wohndistanz der Bevölkerung aus Bosnien-Herzegowina ist etwas schwächer. Nahezu ident sind die Indices im Fall der kroatischen sowie der serbischen Wohnbevölkerung. Die Wohngebiete der Deutschen und jene der Inländer sondern sich am wenigsten voneinander.

Tabelle 10: Dissimilaritätsindizes auf der Ebene der Zählsprengel - Vergleich der Eingebürgerten/Nichteingebürgerten nach Herkunftsländern mit Österreichern 2001

\begin{tabular}{lrrr}
\hline & $\begin{array}{r}\text { Eingebürgerte/ } \\
\text { Österreicher }\end{array}$ & $\begin{array}{r}\text { Ausländer/ } \\
\text { Österreicher }\end{array}$ & $\begin{array}{r}\text { 2. Generation/ } \\
\text { Österreicher }\end{array}$ \\
\hline Serbien und Montenegro & 25,3 & 45,7 & 49,5 \\
Türkei & 36,7 & 51,6 & 56,8 \\
Bosnien-Herzegowina & 33,1 & 47,5 & 55,8 \\
Deutschland & 17,5 & 33,3 & 48,7 \\
Polen & 23,3 & 40,3 & 58,9 \\
Kroatien & 28,2 & 45,6 & 56,1 \\
\hline
\end{tabular}

Quellen: Sonderauswertung MA 66, Volkszählung 2001; eigene Berechnungen.

Der räumliche Effekt, den die Einbürgerung auf die Wohnsegregation ausübt, wird bei einem Vergleich der Dissimilaritätsindizes der eingebürgerten Subgruppen unterschiedlicher ethnonationaler Herkunft deutlich. Die Indexwerte sind für alle Herkunftsländer beträchtlich niedriger als im Falle der Nichteingebürgerten. Am geringsten ist die räumliche Distanz der eingebürgerten Deutschen gegenüber den Inländern, am stärksten sondern sich auch nach dem Wechsel der Staatsbürgerschaft die Wohngebiete der Österreicher türkischer Herkunft von jenen der Österreicher ohne Migrationshintergrund. Zwischen diesen beiden Extremen positionieren sich die räumlichen Verteilungen der ehemaligen polnischen Staatsbürger sowie jene der eingebürgerten Serben. Eingebürgerte aus Bosnien-Herzegowina distanzieren sich am deutlichsten von den Inländern.

\subsubsection{Die räumliche Verteilung der Herkunftsgruppen}

Einen Überblick über die Verteilungsmuster der größten Migrantengruppen in Wien bieten die folgenden Karten. Diese belegen, dass in räumlicher Hinsicht ein permanenter Vermischungsprozess der inländischen und der Wohnbevölkerung mit 
Migrationshintergrund stattfindet. Allerdings stehen Zählsprengeln mit hohen Anteilen der jeweiligen Immigrantengruppe solche mit geringen gegenüber. Die Segregationsmuster sind sehr unterschiedlich ausgeprägt. Die in Wien lebenden Serben segregieren sich ,anders“ im Stadtraum als die Kroaten, die Deutschen oder die Polen. Das Charakteristische der residentiellen Segregation der ,unterschichtenden“ Komponente der ausländischen Wohnbevölkerung in Wien ist deren Kleinräumigkeit (Lichtenberger 1990: 51, 176). Also bestehen Wohnkonzentrationen einzelner Herkunftsgruppen auf kleinräumiger Ebene, gleichzeitig sind aber auch Diffusions- sowie Sukzessionsprozesse nachzuweisen.

\subsubsection{Serbien und Montenegro}

Karte 1: Anteile der Bürger von Serbien-Montenegro an der Wohnbevölkerung auf der Ebene der Zählsprengel 2001

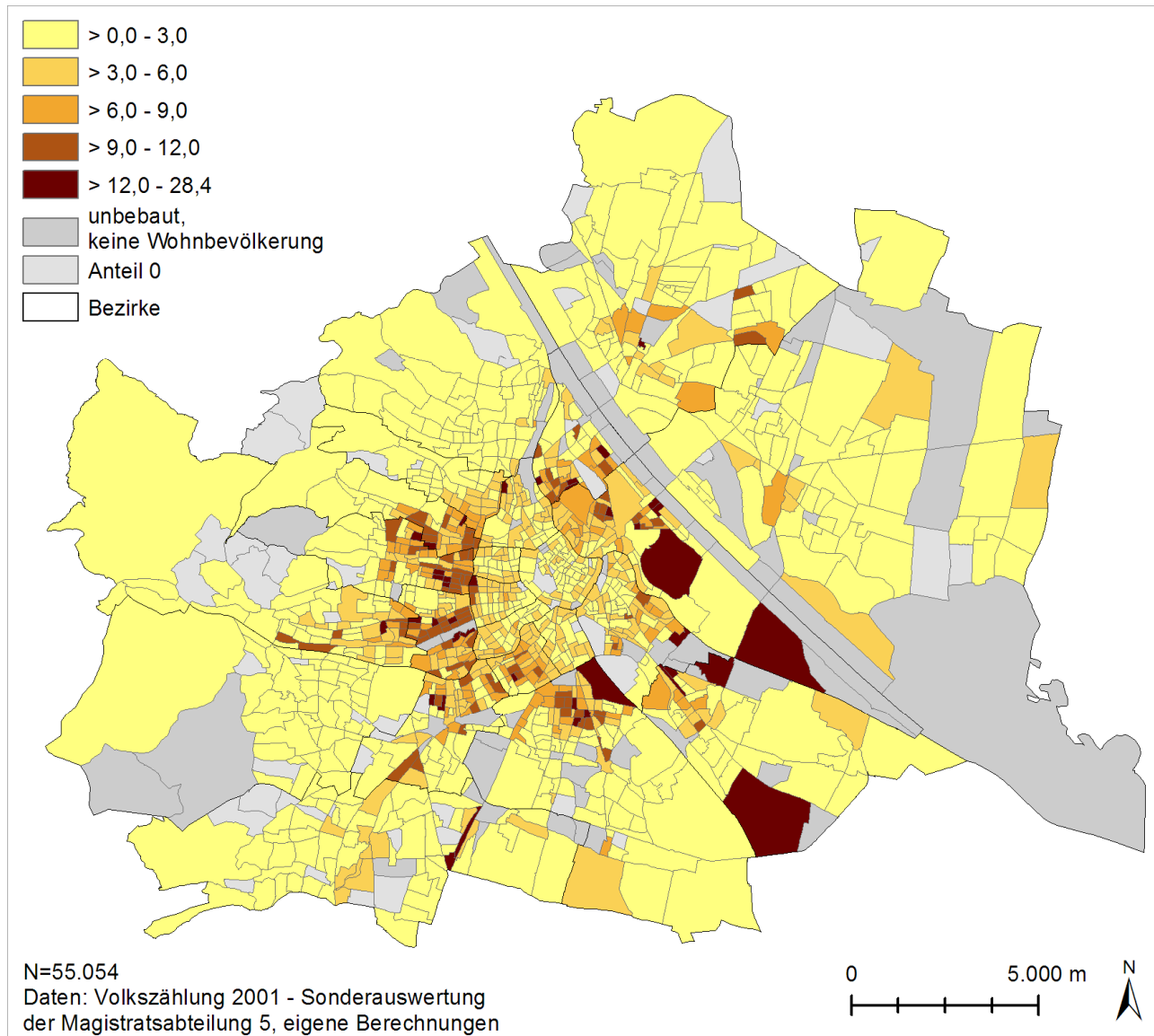

der Magistratsabteilung 5 , eigene Berechnungen

Bearbeitung: ISR, Marco Helbich 
Die Bürger Serbien-Montenegros (vgl. Karte 1) bewohnten 2001 vor allem den Ring an Gastarbeiterbezirken, der, an den Gürtel angelagert, die inneren Bezirke Wiens umgibt. In die Innenbezirke eingestreut fanden sich Zählsprengel mit niedrigeren Anteilen serbischer Wohnbevölkerung. In Teilen der Brigittenau und der Leopoldstadt beliefen sich die Anteile auf 9,1 bis $12 \%$ und zum Teil auf bis 28,4\%. Analoge Konzentrationen kennzeichneten Teile von Ottakring, Hernals, Rudolfsheim-Fünfhaus und Meidling und reichten bis nach Margareten. An den Gürtel angelagert waren hohe Anteile serbischer Wohnbevölkerung auch im 10. und 11. Bezirk zu finden. Die Konzentrationstendenz dieser Migrantengruppe in Gürtelnähe war als räumliches Phänomen 2001 also weiterhin aufrecht.

\section{Karte 2: Anteile der eingebürgerten Serben und Montenegriner an der Wohnbevölkerung} auf der Ebene der Zählsprengel 2001

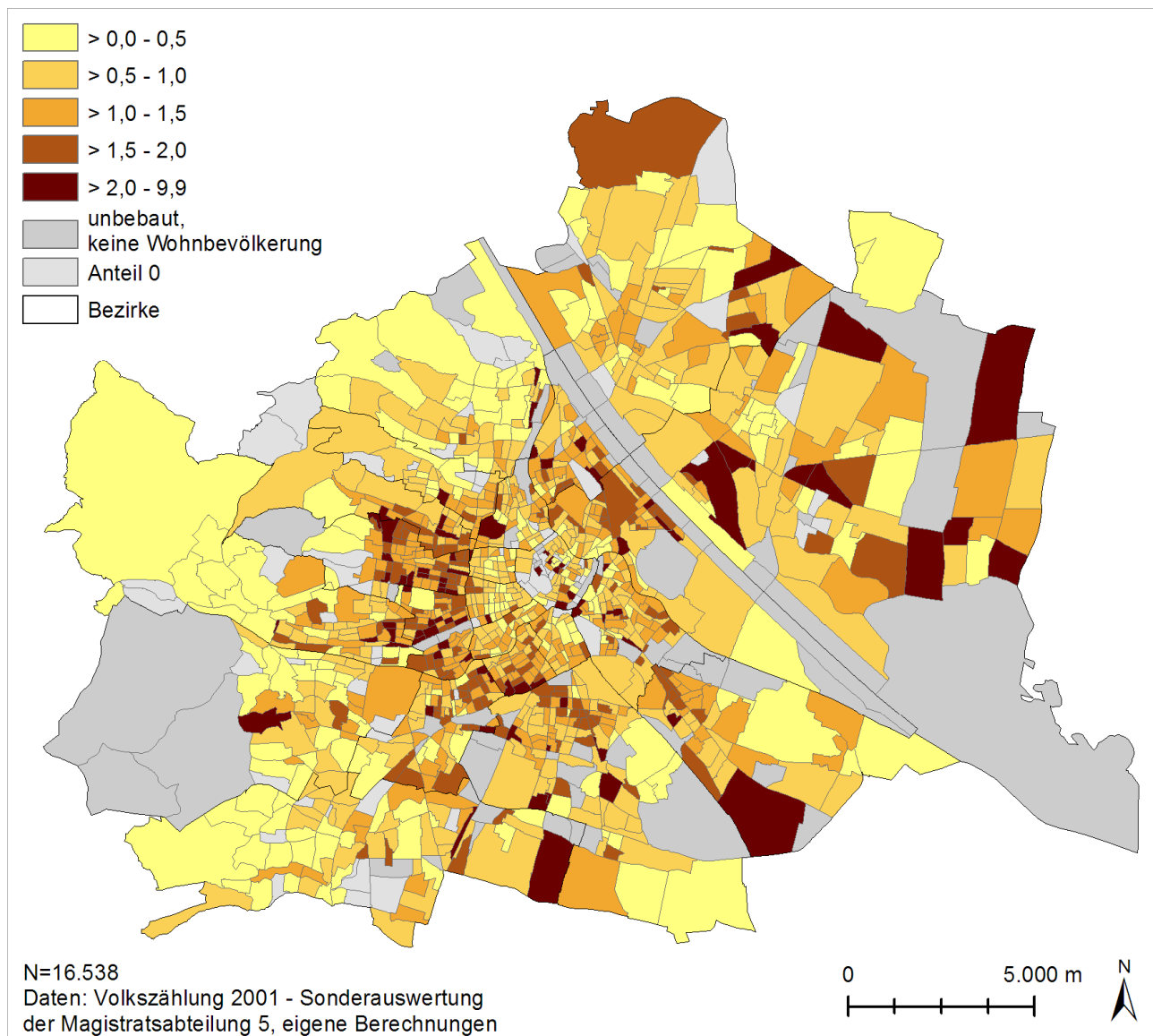

der Magistratsabteilung 5, eigene Berechnungen

Bearbeitung: ISR, Marco Helbich 
Die eingebürgerten Serben haben, wie Karte 2 veranschaulicht, zum Teil die Ausländerbezirke verlassen und sich über den Stadtraum ausgebreitet. Am geringsten ist ihre Präsenz in den Cottagebezirken sowie im Nordwesten des Stadtgebiets. Die höchsten Konzentrationen manifestieren sich in Form eines ringförmigen Verteilungsmusters, das sich vom 17. und 16. über weite Teile des 15. und 12. Bezirks nach Margareten hineinreichend bis nach Favoriten erstreckt. Auch im 20. Gemeindebezirk erreicht die Wohnpräsenz eingebürgerter Serben in etlichen Zählsprengeln bis 9,9\%. Sie haben sich auch über die innerhalb des Gürtels gelegenen Gemeindebezirke ausgebreitet, sind auch an der südlichen Peripherie sowie im 21. und 22. Bezirk mit zum Teil beträchtlichen Anteilen in der Wohnbevölkerung vertreten.

Das Verteilungsmuster der zweiten Generation aus Serbien und Montenegro entspricht den traditionellen Gastarbeiterbezirken. Die Anteilswerte belaufen sich hier in zahlreichen, klumpig gehäuften Zählsprengeln auf bis zu 8,1\%. Zu erwähnen sind hier insbesondere die Bezirke 17, 16, 15, 12, 5 und 10, weiters der 20. und etliche Zählsprengel des 2. Wiener Gemeindebezirkes. Den räumlichen Einheiten mit den höchsten Werten zweiter Generation lagern sich zahlreiche weitere Zählsprengel an, in denen die Präsenz dieser Gruppe Werte zwischen 1,1 und 2\% erreicht.

\subsubsection{Türkei}

Ein Vergleich der zahlenmäßig größten Gruppen von Zuwanderern, welche als ehemalige „Gastarbeiter“ bereits am längsten in der Bundeshauptstadt ansässig sind, verdeutlicht im Falle der Türken ein starkes Ausmaß an residentieller Konzentration auf die klassischen Gastarbeiterbezirke sowie auf die schlecht ausgestattete Gründerzeitwohnsubstanz. Das grundlegende Distributionsmuster der türkischen Zuwanderung hat sich seit Jahrzehnten wenig verändert. Einer Verstärkung der Konzentrationstendenzen in einigen Zählsprengeln steht allerdings eine Reduktion der Konzentration in anderen statistischen Einheiten gegenüber (vgl. Karte 3). Räumliche Konzentrationen türkischer Wohnbevölkerung manifestieren sich rund um den Augarten, im 2. und vor allem im 20. Bezirk. Zahlreiche türkische Staatsbürger leben zwischen dem Frachtenbahnhof Nordwestbahnhof und dem Handelskai in der Brigittenau sowie im Stuwerviertel und im Gebiet um den Mexikoplatz in der Leopoldstadt. Großräumige Akkumulationen von Zählsprengeln mit hohen Anteilen türkischer Bewohner kennzeichnen die gürtelnahen Bereiche von Hernals und Ottakring, große Teile von RudolfsheimFünfhaus, Teile Meidlings und Margaretens sowie Favoriten zwischen Gürtel und Südbahnhof.

Die Wohngebiete der Wiener Türken sind weitgehend ident mit dem noch existierenden Bestand an hochgründerzeitlichen Massenwohnbauten, der durch kleine Wohneinheiten und substandardmäßige Ausstattung gekennzeichnet ist. In niedrigeren Anteilen greift die türkische Wohnbevölkerung auch in den gründerzeitlichen Baubestand der Bezirke 6 und 7 sowie partiell in den 4. Bezirk aus. In die westlichen und südlichen Bezirke sowie ans jenseitige Donauufer war die türkische Bevölkerung auch 
im Jahre 2001 erst in geringen Anteilen (0,1 bis 2\%) vorgedrungen. Der 21. und 22. Bezirk sind für türkische Migranten nach wie vor eher unübliche Wohngegenden. Dies gilt auch für die wienerwaldnahen Cottagedistrikte. Die präferierten Wohngebiete der Türken legen sich also wie ein Ring um die Innere Stadt und die Innenbezirke.

\section{Karte 3: Anteile der türkischen Staatsbürger an der Wohnbevölkerung auf der Ebene der} Zählsprengel 2001

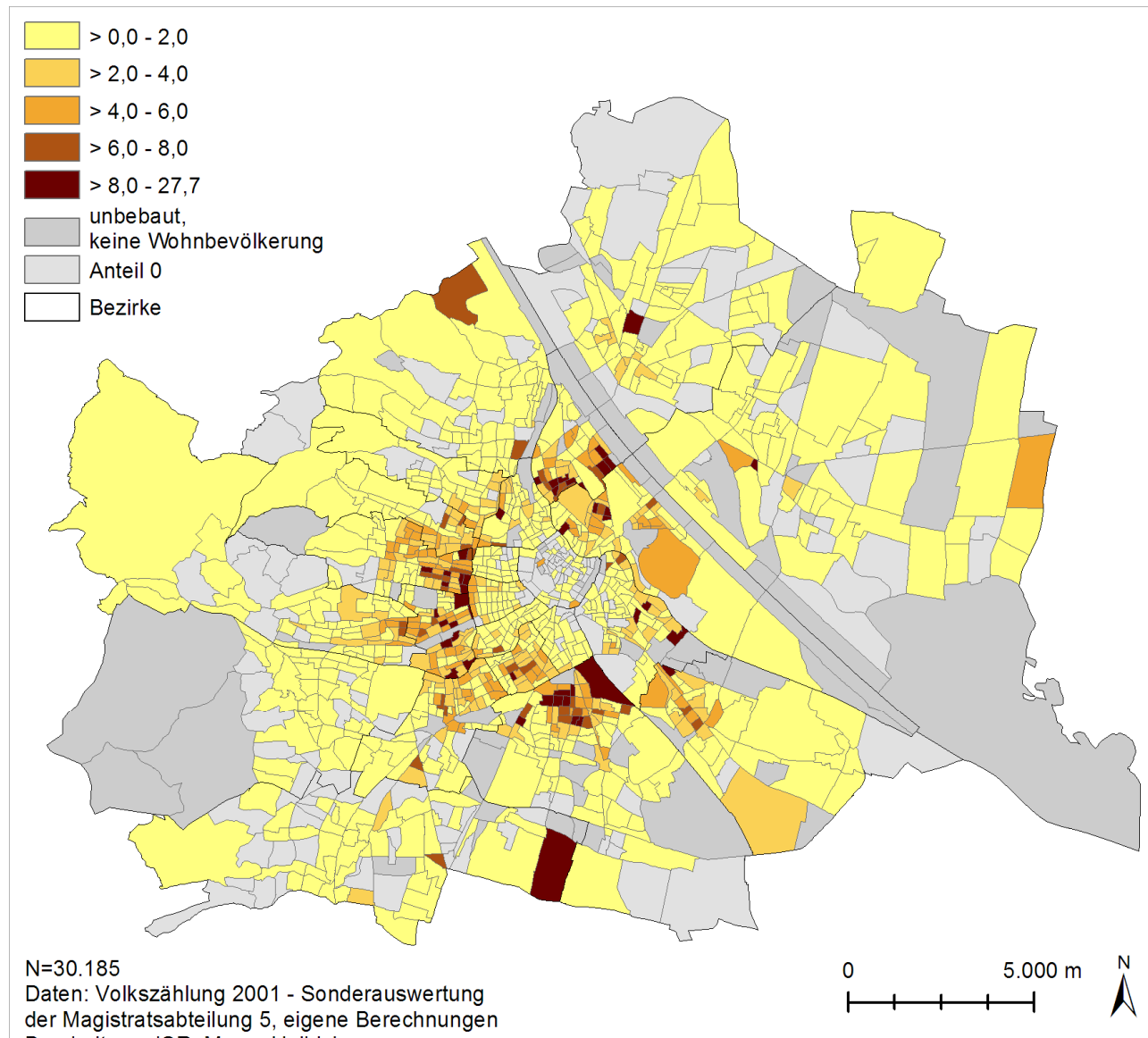

der Magistratsabteilung 5, eigene Berechnungen

Bearbeitung: ISR, Marco Helbich

Die sich im Verlauf der 1990er Jahre verstärkende Einbürgerungsneigung unter der türkischen Wohnbevölkerung zeitigt, wie Karte 4 dokumentiert, räumliche Konsequenzen. Neoösterreicher türkischer Herkunft haben sich (zwar nur in Anteilen von bis zu 1\%) bereits über große Teile des Stadtraumes ausgebreitet. So wohnten sie 2001 auch in den westlichen Außenbezirken, in der südlichen Peripherie, in Floridsdorf und Donaustadt. Die höchsten Konzentrationen dieser Subgruppe bestehen nach 
wie vor in den Arbeiterbezirken - hier werden Anteile von bis zu 5,9\% erreicht. Eine gewisse Abwanderungstendenz der eingebürgerten Türken, z.B. in Kommunalwohnungen, war 2001 deutlich nachweisbar.

\section{Karte 4: Anteile der eingebürgerten Türken an der Wohnbevölkerung auf der Ebene der} Zählsprengel 2001

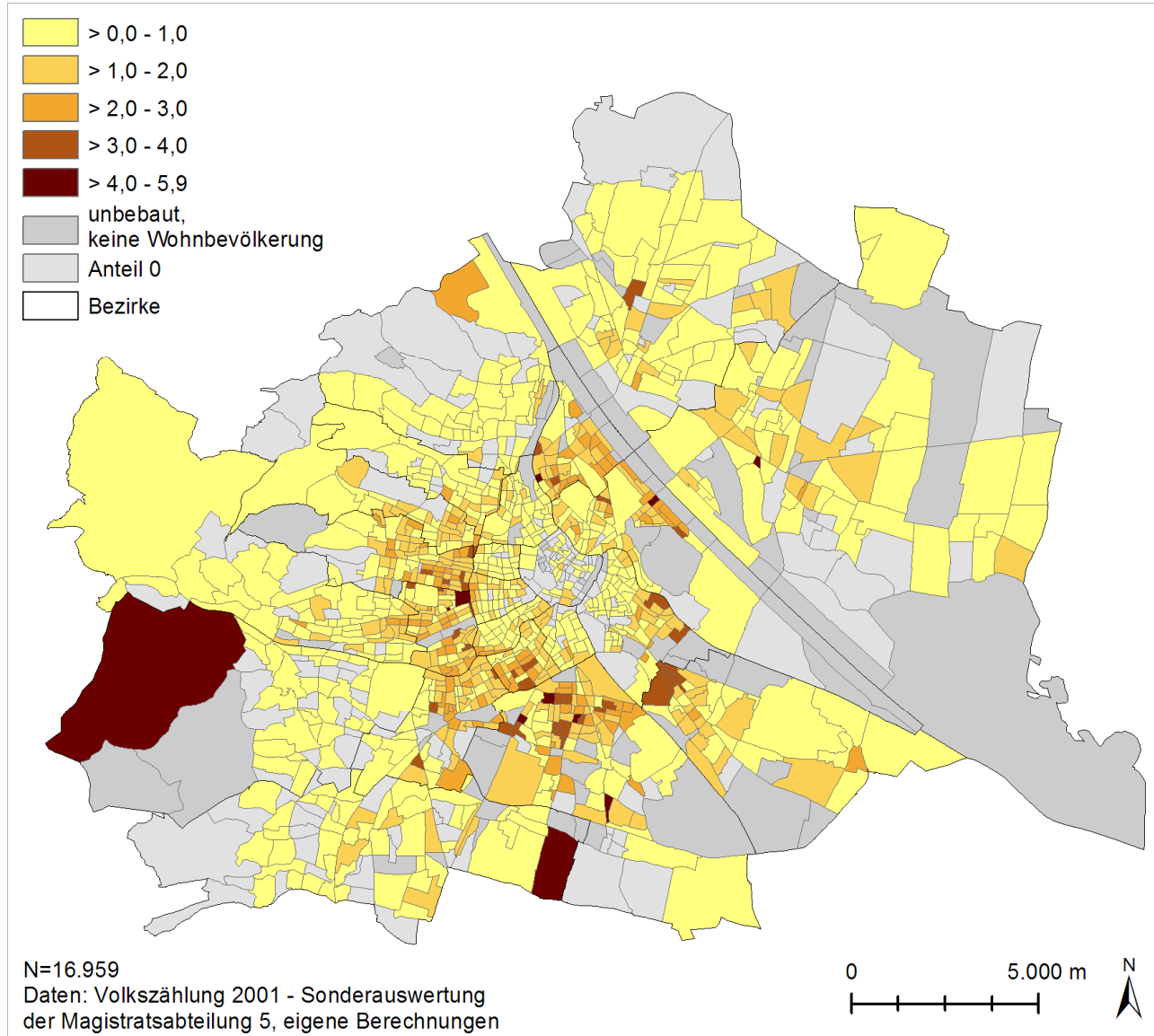

der Magistratsabteilung 5 , eigene Berechnungen

Bearbeitung: ISR, Marco Helbich

Die zweite Generation der Türken hat die traditionellen Arbeiterwohndistrikte bislang nur in geringem Ausmaß verlassen. Segregations- und Konzentrationstendenzen weisen in dieser Herkunftsgruppe also ein hohes Beharrungsvermögen auf. Die höchsten Anteile entfallen auf die Gürtelzone und greifen von hier nach Westen und Süden weit in die Bezirke 17, 16, 15, 12 und 10 aus. 


\subsubsection{Bosnien-Herzegowina}

Eine zahlenmäßig seit dem Flüchtlingszustrom im Gefolge des Balkankriegs bedeutende Gruppe aus dem ehemaligen Jugoslawien ist jene aus Bosnien-Herzegowina (vgl. Karte 5). ${ }^{9}$

Karte 5: Anteile der Staatsbürger Bosnien-Herzegowinas an der Wohnbevölkerung auf der Ebene der Zählsprengel 2001

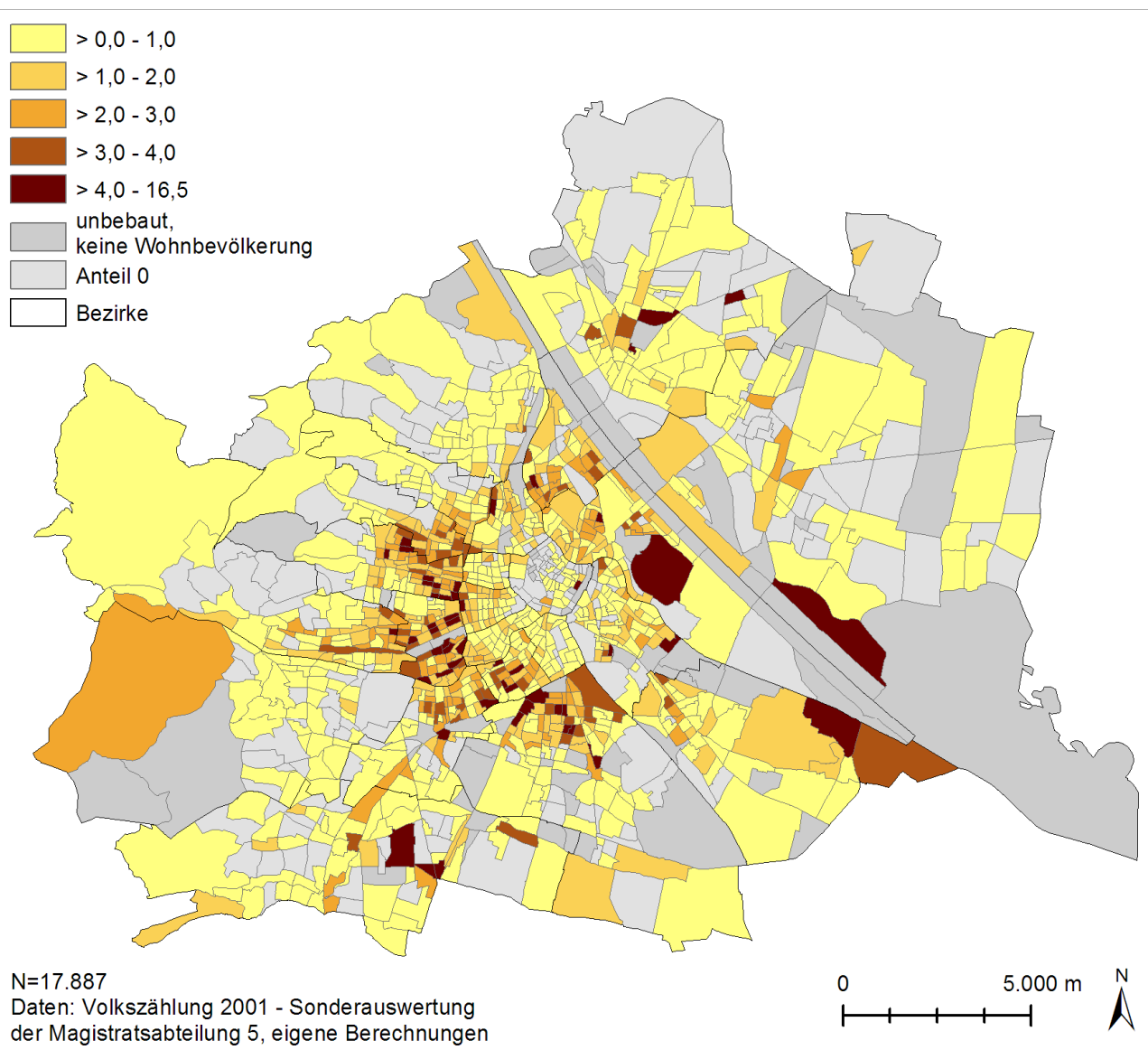

der Magistratsabteilung 5, eigene Berechnungen

Bearbeitung: ISR, Marco Helbich

In dieser Karte sind die 8.513 Personen, die in Bosnien-Herzegowina geboren wurden und eine andere Staatsbürgerschaft besitzen, nicht berücksichtigt. In den Analysen zum Konzentrationsindex wurden sie der Gruppe der „Ausländer“ zugerechnet. 
Die Wohngebiete der Bosnier liegen in den ehemaligen Arbeiterbezirken und bilden ein ringförmiges Verteilungsmuster um die Innenbezirke. Sie umfassen den 2. und 20. Bezirk ebenso wie westlich entlang des Gürtels Ottakring, Hernals, RudolfsheimFünfhaus, Meidling und Favoriten, reichen in diese Bezirke hinein und greifen nach Margareten aus. Die Anteilswerte belaufen sich hier auf 2,1 bis 3\%, liegen aber auch darüber und erreichen Werte bis 16,5\%. Kleinräumige Konzentrationen mit analog hohen Anteilen sind auch im 3., 11. und 23. Bezirk lokalisiert.

Die eingebürgerten Bosnier sind in erster Linie in den Arbeiterbezirken jenseits des Gürtels ansässig, ihre Wohngebiete reichen aber auch in die inneren Gemeindebezirke hinein. In den Bezirken 17, 16, 15 und 12 liegen in zahlreichen Zählsprengeln die Anteile der aus Bosnien-Herzegowina stammenden Neoösterreicher zwischen 1,1 und $2 \%$, in einigen bis zu 6,5\%. Die Siedlungszone umfasst weiters den 5 . und Teile des 10. Bezirks, zentrumsnahe Bereiche des 2. und 3. Gemeindebezirks sowie Teile der Brigittenau. Zum Teil finden sich Zählsprengel mit hohen Anteilen dieser Gruppe auch in den Innenbezirken, hier allerdings in Form eines unregelmäßigen Verteilungsmusters. Inselartig sind einzelne Zählsprengel mit hohen Anteilen auch in Liesing, in Simmering und jenseits der Donau zu finden.

Die zweite Generation der Bosnier verteilt sich in geringen Prozentwerten $(0,1$ bis $0,5 \%$ ) dispers über den Wiener Stadtraum, ist aber vor allem dies- und jenseits des Gürtels in den klassischen Arbeiterbezirken zu finden. Zählsprengel mit höheren Anteilen $(0,6$ bis 2,6\%) sind in Form lokaler Akkumulationen in erster Linie in den Bezirken westlich außerhalb des Gürtels vorhanden. Analoges kann für den 10. und den 20. Bezirk ausgesagt werden.

\subsubsection{Deutschland}

Die Deutschen sind in Wien die zahlenmäßig größte Gruppe von Zuwanderern aus dem Raum der Europäischen Union und typische Elitemigranten (vgl. Karte 6). Die höchsten Konzentrationswerte werden im Stadtzentrum sowie in den angrenzenden bürgerlichen Innenbezirken mit repräsentativem, gründerzeitlichem Baubestand erreicht. Eine weitere Verdichtungszone zieht sich entlang der westlichen Peripherie von Norden nach Süden über die Zählsprengel in den guten Lagen der Cottagebezirke in Wienerwaldnähe. Weiters haben sich großräumige Verdichtungsmuster von statistischen Einheiten herausgebildet, in denen die Anteile der Deutschen an der Wohnbevölkerung bis zu 5,6\% betragen. Eine solche deckt die Innere Stadt und die inneren Bezirke ab, eine weitere ist im Westen lokalisiert und hat sich seit 1991 über Döbling und Währing, den Westen von Ottakring und Hernals sowie den 13., 14. und 23. Bezirk ausgebreitet. Nur niedrige Anteile entfallen auf die traditionellen Arbeiterbezirke entlang des Gürtels und im Süden der Stadt. Floridsdorf und Donaustadt sind Wohngebiete von geringer Beliebtheit.

Neoösterreicher deutscher Herkunft bleiben jenen Bezirken treu, in denen auch das Gros der nichteingebürgerten Deutschen ansässig ist. Einmal mehr ist es also der Westen Wiens, der in der Wohngunst hoch rangiert. Allerdings sind die Anteilswerte die- 
ser Subgruppe auf Zählsprengelebene durchwegs geringer (zumeist bis 2 oder höchstens 3\%) als jene der deutschen Staatsbürger.

\section{Karte 6: Anteile der deutschen Staatsbürger an der Wohnbevölkerung auf der Ebene der} Zählsprengel 2001

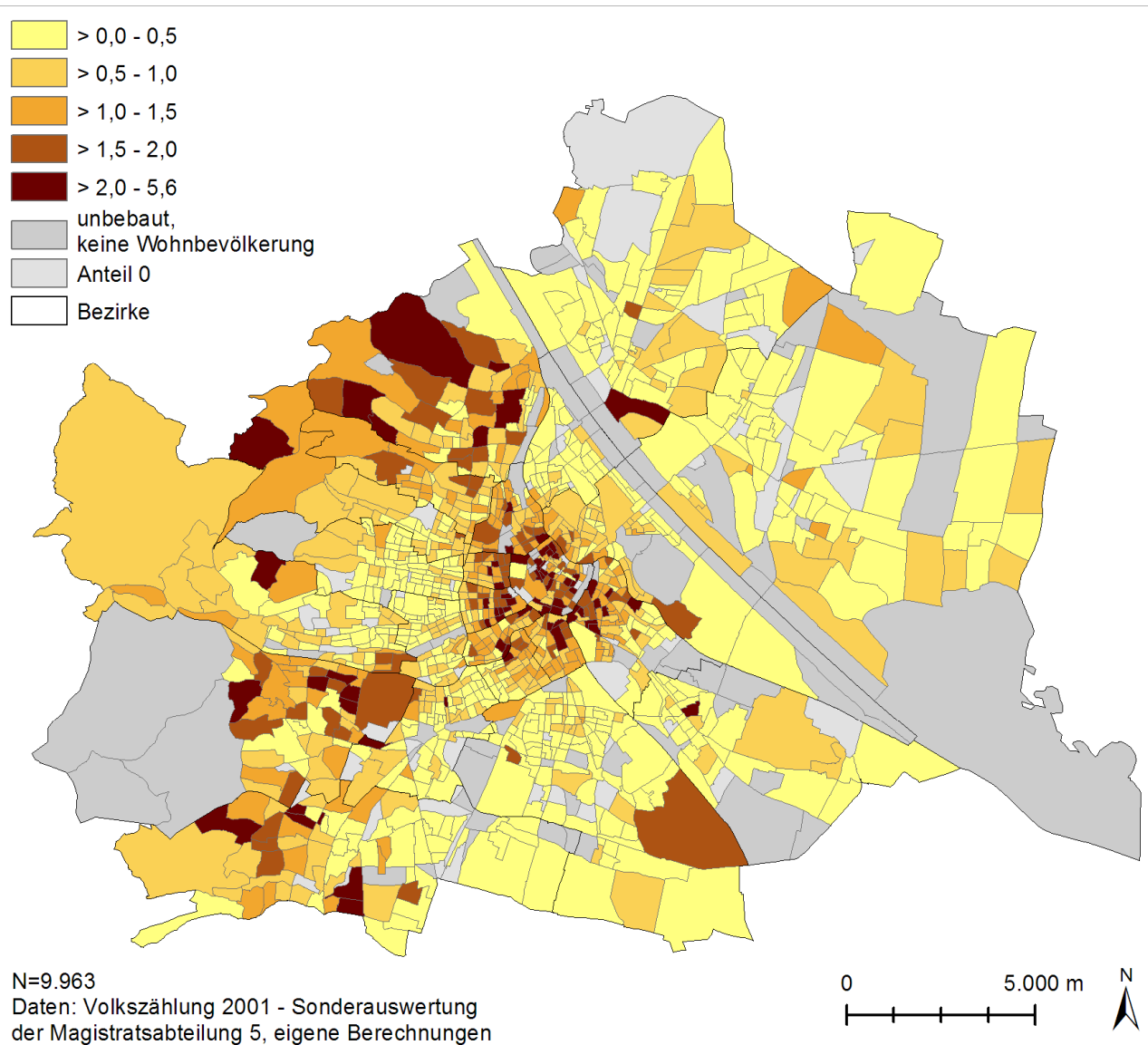

der Magistratsabteilung 5, eigene Berechnungen

Bearbeitung: ISR, Marco Helbich

Die zweite Generation der deutschen Immigration tritt nur in wenigen Zählsprengeln quantitativ stärker auf. Diese räumlichen Einheiten sind vor allem rund um das Stadtzentrum sowie im äußersten Nordwesten und Südwesten lokalisiert, bilden aber kein markantes Verteilungsmuster. 


\subsubsection{Polen}

Die polnische Zuwanderung belegt ein geringeres Ausmaß an Segregationstendenzen als im Falle der „Exgastarbeiter“. Zwar sind (vgl. Karte 7) die als „Ausländerbezirke“ titulierten Bezirke 15, 16 und 17, sowie Margareten, die Leopoldstadt und die Brigittenau durch die höchsten Anteile polnischer Bürger in der Wohnbevölkerung charakterisiert, darüber hinaus sind solche statistische Einheiten aber auch außerhalb der Gürtelzone zu finden.

Karte 7: Anteile der Staatsbürger Polens an der Wohnbevölkerung auf der Ebene der Zählsprengel 2001

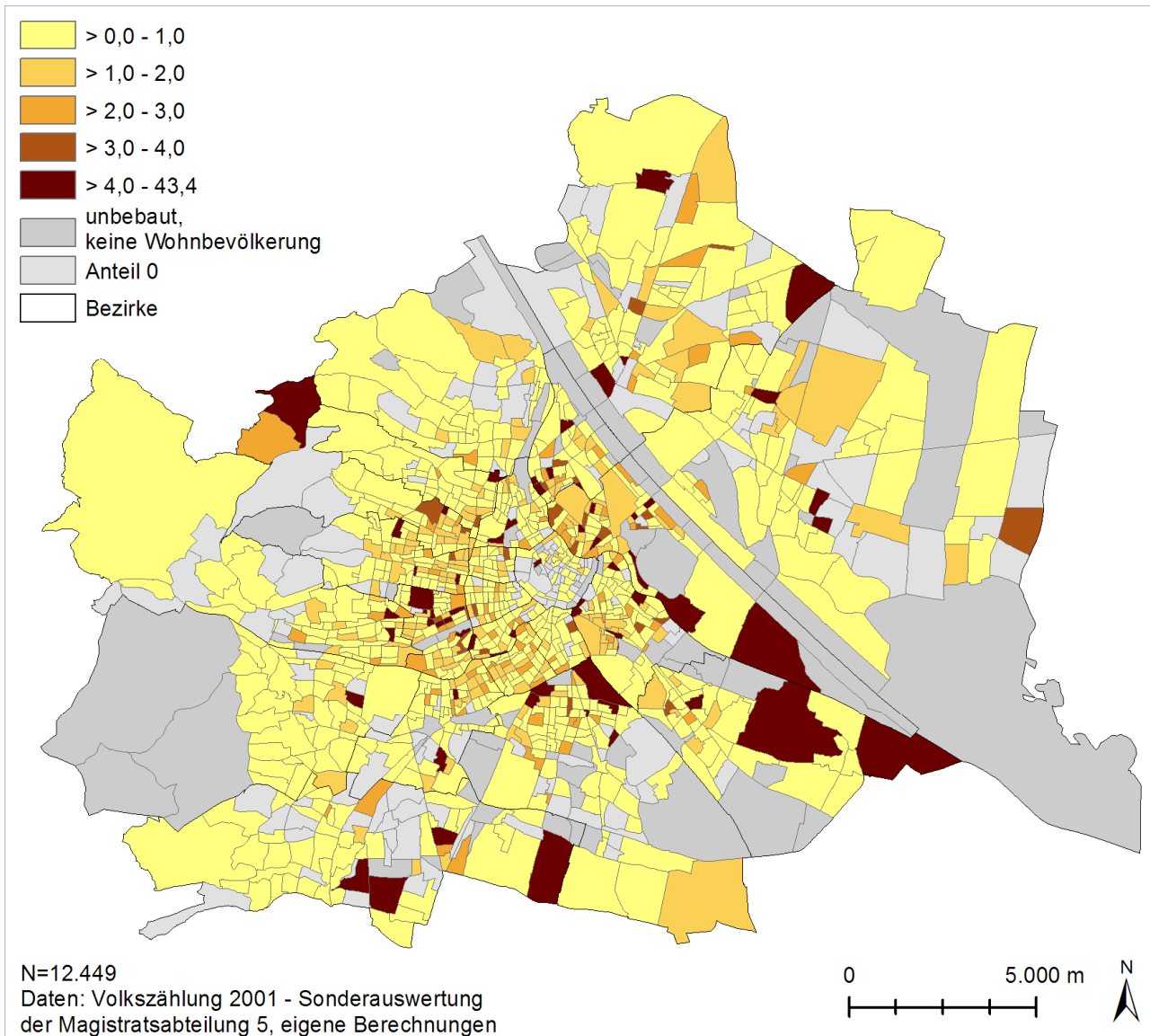

der Magistratsabteilung 5 , eigene Berechnungen Bearbeitung: ISR, Marco Helbich

2001 diffundierte die polnische Bevölkerung bereits über große Teile des Wiener Stadtraums. Ihre Präsenz lag in den Villen- und Einfamilienhausperipherien noch bei 
bescheidenen Werten, aber der Diffusionsprozess hatte die inneren Bezirke (außer den 1.), großräumig die an den Westgürtel anschließenden Bezirksteile sowie auch den Süden des Stadtgebietes (3, 10. und 11. Bezirk), die Wohngegenden entlang der Donau (2. und 20. Gemeindebezirk) und Zählsprengel in Floridsdorf und Donaustadt erfasst. Polnische Wohnenklaven hatten sich auch im 23. und 10. Bezirk herausgebildet.

Der eingebürgerte Teil der „Polonia“ hat sich bereits über nahezu das gesamte Wiener Stadtgebiet ausgebreitet. Zum Unterschied von den „Gastarbeitern“ bestehen jedoch keine ausgeprägten Konzentrationstendenzen. Zählsprengel mit höheren Anteilen (bis zu 4,7\%) eingebürgerter Polen sind unregelmäßig verteilt. Sie finden sich in der Innenstadt genauso wie in den bürgerlichen Innenbezirken, in den Arbeiterquartieren ebenso wie in den Cottagevierteln sowie in der Neubau- und Einfamilienhausperipherie im Süden der Stadt und jenseits der Donau. Die Verteilung der „Polonia“ zeugt von der erfolgreichen Integration in alle Segmente des Wiener Wohnungsmarktes und auch von einer geglückten Integration auf allen Hierarchieebenen des lokalen Arbeitsmarktes. Wohnkonzentrationen sind zwar vorhanden, verbleiben aber auf kleinräumiger Ebene.

In Österreich geborene Polen und Polinnen sind sowohl in den inneren Bezirken als auch in den Gemeindebezirken westlich des Gürtels, in Liesing und Favoriten, in Leopoldstadt und in Brigittenau sowie jenseits der Donau ansässig. Das räumliche Verteilungsmuster präsentiert sich uneinheitlich und weist auf keine Konzentrationen hin.

\subsubsection{Kroatien}

Eine seit der Gastarbeiterzuwanderung wichtige Herkunftsgruppe bilden die Kroaten. Diese konzentrieren sich vor allem auf die klassischen Gastarbeiterbezirke (vgl. Karte $8^{10}$ ). In Hernals, Ottakring, Rudolfsheim-Fünfhaus, Meidling und Margareten, liegt die anteilsmäßige Präsenz dieser Migrantengruppe im Bereich zwischen 1,1 und $1,5 \%$, beträgt in einzelnen statistischen Raumeinheiten aber auch bis zu 6,1\%. In Favoriten sind analoge Prozentsätze auch in gürtelferneren Zählsprengeln zu finden, vereinzelt auch im 11. Wiener Gemeindebezirk. In Form eines dispersen Verteilungsmusters sind höherer Anteile kroatischer Wohnbevölkerung auch in den inneren Bezirken, in der Innenstadt sowie im 2. und 20. Bezirk vorhanden. Jenseits der Donau sowie an der westlichen und südlichen Peripherie waren Bürger Kroatiens nur in geringen Anteilen wohnhaft.

Die Subgruppe der eingebürgerten Kroaten lässt bezüglich ihrer Verteilung kein Konzentrationsmuster erkennen. In geringen Anteilen (bis 0,5\%) haben sich die eingebürgerten Kroaten bereits über viele Bezirke ausgebreitet. Am ehesten finden sich

10 In dieser Karte sind die 7.689 Personen, die eine kroatische Staatsbürgerschaft besitzen, aber in einem anderen Land (dem ehemaligen Jugoslawien) geboren wurden, nicht berücksichtigt. In den Analysen zum Konzentrationsindex und den Abbildungen zu den Bezirken wurden sie der Gruppe „Ausländer“ hinzugerechnet. 
Zählsprengel mit zwischen 1,1 und 3,3\% liegenden Anteilen eingebürgerter Kroaten im Stadtzentrum, vereinzelt in den Innenbezirken sowie entlang des Gürtels in den westlichen Gastarbeiterbezirken.

Karte 8: Anteile der Staatsbürger Kroatiens an der Wohnbevölkerung auf der Ebene der Zählsprengel 2001

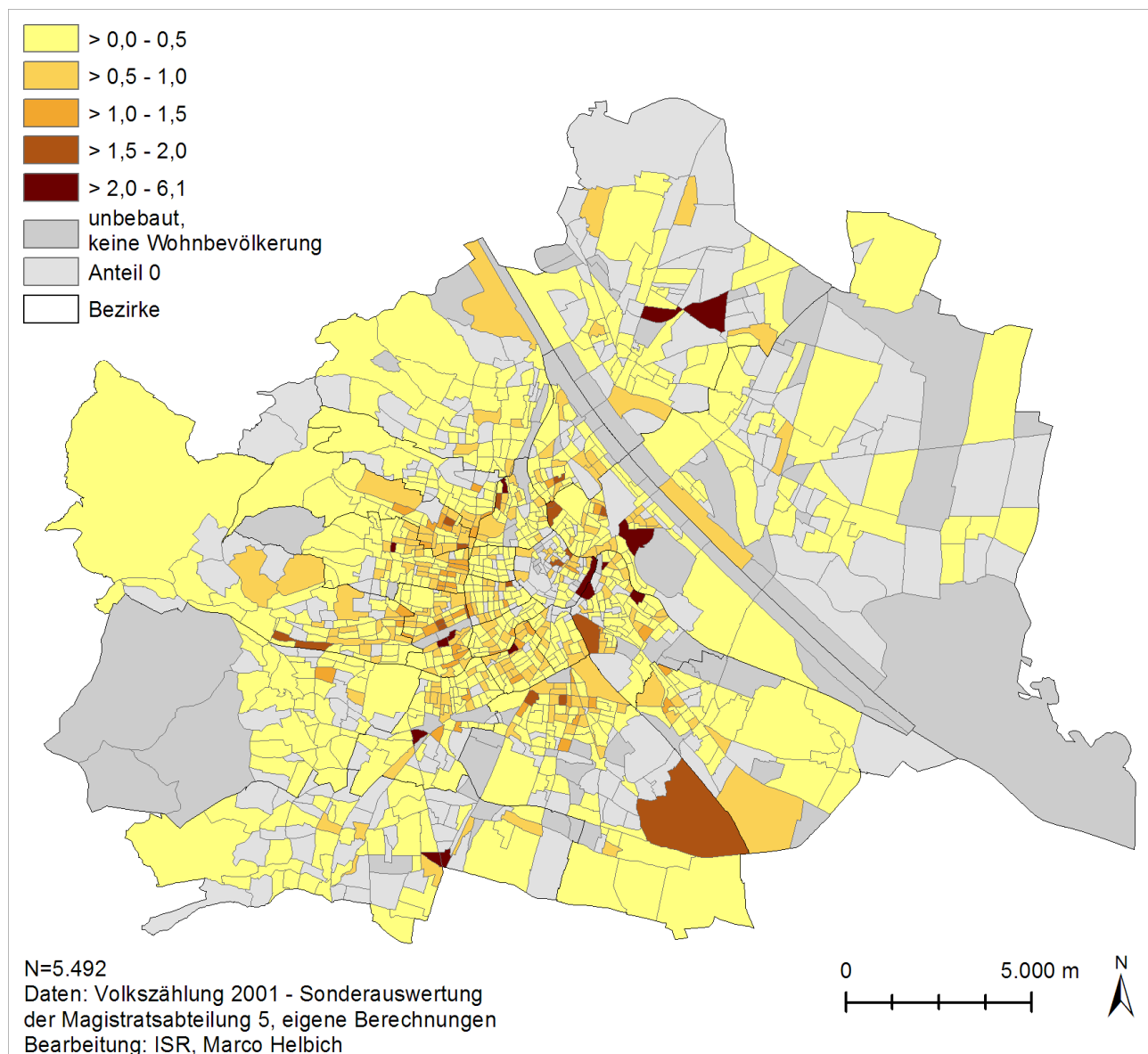

Die zweite Generation kroatischer Staatsbürger ist vor allem in den westlichen Außenbezirken in der Nähe des Gürtels ansässig, aber auch in diesen Wohnvierteln ist die Präsenz dieser Gruppe bescheiden. Sie übersteigt in den meisten Zählsprengeln nicht die 1-\%-Marke. Kleinere Häufungen solcher Zählsprengel charakterisieren weiters den 10. und den 20. Wiener Gemeindebezirk. Diese Gruppe ist also am ehesten in den traditionellen Wohnvierteln der „Gastarbeiter“ zu finden. 


\subsection{Zur Wohnsituation 2001: Österreicher mit und ohne Migrationshintergrund sowie ausländische Staatsbürger im Vergleich}

Aus der Zusammenführung von Resultaten der Volks-, Häuser- und Wohnungszählung $^{11}$ können Schlussfolgerungen über die konkrete Wohnsituation der ausländischen Bevölkerung unter Berücksichtigung der Einbürgerung abgeleitet werden. Wohnen Eingebürgerte in qualitativ hochwertigeren Wohnungen und steht ihnen mehr Wohnraum zur Verfügung als ihren noch nicht eingebürgerten Landsleuten? Leben sie verstärkt in Gemeindewohnungen? Ist ein Mobilitätstrend aus dem gründerzeitlichen Altbau in Wohnungen neueren Errichtungsdatums zu konstatieren?

Vorweg ist zu sagen, dass Unterschiede in der Wohnsituation zwischen den Eingebürgerten und den ausländischen Staatsangehörigen in Abhängigkeit von dem jeweiligen Analysekriterium mehr oder minder ausgeprägt zu Tage treten. Hierbei manifestieren sich auch gruppenspezifische Unterschiede. Das heißt, es sind nicht nur die Einbürgerung oder die Aufenthaltsdauer, welche die Wohnungsmarktpositionierung determinieren, sondern eine Vielzahl weiterer Variablen, wie Arbeitsmarktpositionierung, Einkommen, Rückkehrabsichten etc., spielt ebenfalls eine erhebliche Rolle.

\subsubsection{Die Ausstattungskategorie}

Die Analyse nach Wohnstandardkategorien dokumentiert die Benachteiligung der ehemaligen „Gastarbeiter" sowie die privilegierte Position der Inländer und der EUMigranten (vgl. Tabelle 11). Von den Österreichern ohne Migrationshintergrund bewohnten 2001 bloß 3,7\% Wohnungen der Kategorie D, während fast 91\% in Kategorie A ansässig waren. Schlechter als die Inländer, jedoch deutlich besser als die ausländischen Staatsbürger wohnten die Eingebürgerten. 85\% von ihnen hatten Wohnungen des besten Ausstattungsstandards zur Verfügung, zugleich war der Anteil, der im Substandard logierte, mit 8,3\% mehr als doppelt so hoch wie bei den Inländern.

Die längere Aufenthaltsdauer und die damit verknüpfte Einbürgerung gehen häufig mit einem Avancement hinsichtlich des Wohnstandards einher. Ausländer müssen sich nach wie vor zu fast $24 \%$ mit Wohnraum der Kategorie D bescheiden und nicht einmal zwei Drittel (66\%) verfügen über Kategorie A. Die Wohnsituation der zweiten Generation spiegelt ebenfalls ein hohes Ausmaß an Benachteiligung wider: $28 \%$ logieren in Kategorie D und 61\% (weniger als bei den Ausländern) in Wohnungen optimalsten Standards.

11 Die Grundlage bilden Personen in Privathaushalten, also etwas weniger als die gesamte Wohnbevölkerung, nämlich 1.517.649 Menschen, denn 32.474 Wienerinnen und Wiener leben in Anstaltshaushalten (2,1\%). 
Tabelle 11: Personen in Privatwohnungen in Wien nach der Ausstattungskategorie, dem Geburtsland und der Staatsangehörigkeit 2001

\begin{tabular}{|c|c|c|c|c|c|}
\hline & insgesamt & A & B & $\mathrm{C}$ & $\mathrm{D}$ \\
\hline Österr. ohne Migrationshintergrund & 1.127 .981 & 90,5 & 4,6 & 1,2 & 3,7 \\
\hline Österr. mit GL im Ausland & 149.740 & 85,1 & 5,4 & 1,2 & 8,3 \\
\hline EU-15 & 20.341 & 90,5 & 4,9 & 1,1 & 3,5 \\
\hline Deutschland & 15.097 & 90,5 & 4,9 & 1,2 & 3,4 \\
\hline „Gastarbeiter“ & 48.551 & 76,4 & 6,3 & 1,4 & 15,9 \\
\hline Bosnien und Herzegowina & 7.875 & 79,0 & 5,3 & 1,1 & 14,6 \\
\hline Serbien u. Montenegro & 16.317 & 77,1 & 6,3 & 1,6 & 15,0 \\
\hline Kroatien & 4.553 & 85,6 & 4,4 & 1,2 & 8,8 \\
\hline Mazedonien & 1.418 & 72,4 & 7,8 & 0,8 & 19,0 \\
\hline Türkei & 16.769 & 71,4 & 7,0 & 1,5 & 20,1 \\
\hline Slowenien & 1.619 & 85,4 & 7,0 & 1,3 & 6,3 \\
\hline Višegrad und Rumänien & 47.320 & 88,7 & 5,3 & 1,3 & 4,7 \\
\hline Polen & 11.862 & 90,0 & 4,4 & 1,0 & 4,6 \\
\hline Rumänien & 5.525 & 90,1 & 4,0 & 1,0 & 4,9 \\
\hline Slowakei & 4.209 & 90,2 & 4,3 & 1,3 & 4,1 \\
\hline Tschechische Republik & 18.163 & 86,9 & 6,7 & 1,7 & 4,8 \\
\hline Ungarn & 7.561 & 89,6 & 4,9 & 1,0 & 4,5 \\
\hline Schweiz & 1.190 & 92,4 & 4,5 & 0,6 & 2,6 \\
\hline Vereinigte Staaten & 840 & 94,0 & 3,5 & 0,4 & 2,1 \\
\hline anderer Staat, unbekannt & 31.498 & 89,0 & 4,5 & 1,0 & 5,5 \\
\hline Nichtösterr. mit GL im Inland & 34.136 & 61,4 & 9,3 & 1,2 & 28,1 \\
\hline Nichtösterr. mit GL im Ausland & 205.792 & 66,0 & 8,9 & 1,3 & 23,7 \\
\hline EU-15 & 20.173 & 91,1 & 4,5 & 0,6 & 3,7 \\
\hline Deutschland & 10.473 & 91,3 & 4,5 & 0,7 & 3,6 \\
\hline „Gastarbeiter“ & 123.109 & 53,9 & 10,8 & 1,7 & 33,6 \\
\hline Bosnien und Herzegowina & 25.852 & 64,5 & 8,2 & 0,9 & 26,4 \\
\hline Serbien u. Montenegro & 55.543 & 50,1 & 11,5 & 2,3 & 36,1 \\
\hline Kroatien & 6.012 & 69,8 & 8,8 & 0,9 & 20,5 \\
\hline Mazedonien & 5.055 & 54,3 & 13,2 & 1,0 & 31,4 \\
\hline Türkei & 29.866 & 48,1 & 11,7 & 1,5 & 38,6 \\
\hline Slowenien & 781 & 73,6 & 7,7 & 0,9 & 17,8 \\
\hline Višegrad und Rumänien & 25.094 & 79,3 & 7,1 & 0,9 & 12,7 \\
\hline Polen & 12.430 & 75,5 & 8,5 & 0,9 & 15,2 \\
\hline Rumänien & 3.490 & 79,0 & 7,2 & 1,3 & 12,5 \\
\hline Slowakei & 2.979 & 82,8 & 4,9 & 0,9 & 11,4 \\
\hline Tschechische Republik & 2.238 & 85,2 & 5,9 & 0,7 & 8,3 \\
\hline Ungarn & 3.957 & 85,4 & 5,2 & 1,0 & 8,5 \\
\hline Schweiz & 1.118 & 89,5 & 5,7 & 0,1 & 4,7 \\
\hline Vereinigte Staaten & 2.078 & 93,6 & 3,7 & 0,1 & 2,7 \\
\hline anderer Staat, unbekannt & 34.220 & 82,3 & 6,8 & 0,9 & 10,1 \\
\hline
\end{tabular}

Quelle: Sonderauswertung von Statistik Austria, Volks-, Gebäude- und Wohnungszählung 2001, eigene Berechnungen. Anmerkung: GL = Geburtsland. 
Beträchtliche Unterschiede manifestieren sich zwischen den Herkunftsgruppen. Die Divergenzen treten insbesondere bei einem Vergleich zwischen EU-Migranten und „Gastarbeitern“ hervor, und zwar sowohl bei Eingebürgerten als auch bei Nichteingebürgerten. 91\% der EU-15-Bürger, aber nur 54\% der ehemaligen „Gastarbeiter“ bewohnten 2001 Kategorie-A-Wohnungen. Während nur 3,7\% der EU-Migranten im Substandard logierten, war der analoge Prozentsatz unter den Exjugoslawen und Türken nahezu zehnmal so hoch. In der Ausstattungskategorie B manifestieren sich ähnliche Unterschiede.

Auch innerhalb der Kategorie der nichteingebürgerten ehemaligen „Gastarbeiter“ divergiert die Wohnungsausstattung. Die Türken repräsentieren die am schlechtesten versorgte Gruppe: 37\% müssen sich mit Substandardwohnungen bescheiden, nur 48\% stehen Wohnungen der besten Standardkategorie zur Verfügung. Die Exjugoslawen weisen diesbezüglich ein hohes Ausmaß an Heterogenität auf: Das Wohnen im Substandard ist unter Serben und Mazedoniern am stärksten verbreitet. Slowenen und Kroaten haben sich erfolgreicher in den Wohnungsmarkt integriert. Nahezu drei Viertel der Slowenen und fast 70\% der Kroaten verfügen über bestausgestatteten Wohnraum.

Besser als bei den Exjugoslawen ist der Wohnstandard der Zuwanderer aus Ostmitteleuropa. Am besten schneiden hier tschechische und ungarische Staatsbürger ab, die nur zu jeweils $8 \%$ im Substandard wohnen. Nur geringfügig schlechter präsentiert sich die Wohnsituation der Slowaken. Polen leben seltener in Kategorie A und etwas häufiger in Kategorie D als Rumänen.

Die Unterschiede treten auch unter den Eingebürgerten auf, allerdings ist die Ausstattungsqualität von deren Wohnungen im Durchschnitt besser als bei ausländischen Staatsbürgern. Wiederum sind die Neoösterreicher aus der Türkei am häufigsten in Substandardwohnungen zu finden, gefolgt von den Österreichern mit einem Geburtsort in Mazedonien. Nur 3,5\% der EU-15-Zuwanderer, aber rund viermal so viele ehemalige „Gastarbeiter“ logieren im Substandardsegment. Drei von vier „Gastarbeitern“, aber mehr als $90 \%$ der in Österreich eingebürgerten EU-Bürger verfügen über topausgestattete Wohnungen. Eingebürgerte Serben positionieren sich besser als nichteingebürgerte. Es sind eingebürgerte Slowenen und Kroaten, die unter den Exjugoslawen den besten Wohnstandard für sich verbuchen. Analog zu den nichteingebürgerten weisen auch die eingebürgerten Ost-West-Migranten eine qualitativ hochwertigere Wohnungsausstattung auf als Neoösterreicher aus der Türkei oder aus Exjugoslawien. Die Anteile des Wohnens im Substandard liegen bei Österreichern aus Ostmitteleuropa bei Werten knapp über 4\%.

Die Unterschiedlichkeiten der Wohnungsausstattung zwischen eingebürgerten und nichteingebürgerten Zuwanderern treten deutlich hervor. Unter den Deutschen sind die mit der Einbürgerung einhergehenden Wohnqualitätsunterschiede am schwächsten ausgeprägt. Unter „Gastarbeitern“ und Ost-West-Migranten weist der Effekt der Übernahme der österreichischen Staatsbürgerschaft in dieselbe Richtung. So hat sich ein mehr als dreimal so hoher Anteil der polnischen Staatsbürger mit Substandardwohnungen zu bescheiden als bei den Eingebürgerten. Auch in der türkischen Herkunfts- 
gruppe wird der Effekt der Einbürgerung deutlich. Fast 39\% der türkischen Staatsbürger leben im Substandard, jedoch nur ein knappes Fünftel ihrer eingebürgerten Landsleute. Simultan dazu geht unter den Eingebürgerten ein Anstieg der Präsenz in Wohnkategorie A einher.

\subsubsection{Das Rechtsverhältnis}

Die Unterschiede hinsichtlich des Rechtsgrundes der Wohnungsbenutzung sagen ebenfalls einiges über die Wohnungsmarktpositionierung von Zuwanderern in Wien aus. Auch in diesem Zusammenhang gilt, dass sich herkunftsgruppenspezifische Unterschiede ebenso manifestieren wie Divergenzen nach dem Kriterium der Einbürgerung. Die Analyse belegt einmal mehr den privilegierten Status von Inländern ohne Migrationshintergrund und EU-15-Zuwanderern (vgl. Tabelle 12).

Eingebürgerte EU-15-Bürger sind zu einem gleich hohen Anteil wie die Inländer ohne Migrationshintergrund Gebäudeigentümer, besitzen häufiger Eigentumswohnungen, gehen aber seltener unbefristete Hauptmietverhältnisse ein. Knapp dahinter positionieren sich die eingebürgerten Ost-West-Migranten. Signifikant schlechter ist der Zugang der eingebürgerten Exjugoslawen und Türken zu Haus- und Wohnungseigentum: Bloß 7\% der eingebürgerten Türken haben sich eine Eigentumswohnung angeschafft, nicht einmal 4\% sind Hauseigentümer.

Migranten der zweiten Generation nehmen gegenüber österreichischen Staatsbürgern eine schlechtere Position auf dem Wohnungsmarkt ein: Nur 8\% sind in den Eigentumssektor eingestiegen, mehr als zwei Drittel nutzen Hauptmietwohnungen.

Diese Verteilung hängt auch mit ihrem häufig temporären Aufenthalt in Österreich zusammen. Demgemäß sind auch die Eigentümerquoten unter den Nichteingebürgerten niedriger als bei den Eingebürgerten. Nichteingebürgerte „Gastarbeiter“ haben es seltener $(67 \%)$ geschafft, eine unbefristete Hauptmietwohnung zu beziehen als die Eingebürgerten (76\%), dafür ist unter den Erstgenannten der Anteil der befristeten Mietverhältnisse viermal so hoch. Die Präsenz des Eigentums bleibt mit in summa $7,1 \%$ bei den Nichteingebürgerten deutlich hinter dem entsprechenden Wert $(10,8 \%)$ bei den eingebürgerten „Gastarbeitern“ zurück. Dienstwohnungen spielen bei nichteingebürgerten Türken und Exjugoslawen eine wichtige Rolle.

Befristete Mietverhältnisse sind unter „Gastarbeitern“ jedoch seltener als bei EUBürgern und Ost-West-Migranten - ein Indiz für den seltener auf Permanenz ausgerichteten Aufenthalt der beiden letztgenannten Gruppen. Višegrad-Bürger sind häufiger Haus- oder Wohnungseigentümer als die „Gastarbeiter“, nutzen aber viel seltener Dienstwohnungen.

Die Unterschiede nach Herkunftsländern sind vielfältig. Unter den nichteingebürgerten ehemaligen „Gastarbeitern“ sind Slowenen und Kroaten am häufigsten, Türken am seltensten Eigentümer einer Wohnung. Gering ist der Eigentümeranteil auch unter den Bürgern Serbien-Montenegros. Mit 74\% ist der Anteil unbefristeter Hauptmieten unter türkischen Staatsbürgern am höchsten. Diese weisen auch äußerst niedrige Ei- 
Tabelle 12: Personen in Privatwohnungen in Wien nach dem Rechtsgrund für die Wohnungsbenützung, dem Geburtsland und der Staatsangehörigkeit 2001

\begin{tabular}{|c|c|c|c|c|c|c|c|}
\hline & insgesamt & $\begin{array}{r}\text { Haupt- } \\
\text { miete } \\
\text { befristet }\end{array}$ & $\begin{array}{l}\text { Haupt- } \\
\text { miete } \\
\text { unbefr. }\end{array}$ & $\begin{array}{r}\text { Gebäu- } \\
\text { deeigen- } \\
\text { tum }\end{array}$ & $\begin{array}{l}\text { Woh- } \\
\text { nungs- } \\
\text { eigent. }\end{array}$ & $\begin{array}{r}\text { Dienst-, } \\
\text { Natu- } \\
\text { ralwhg. }\end{array}$ & $\begin{array}{r}\text { sonst. } \\
\text { Rechts- } \\
\text { verh. }\end{array}$ \\
\hline Österr. ohne Migrationshinterg. & 1.127.981 & 3,1 & 72,1 & 7,8 & 12,2 & 2,5 & 2,2 \\
\hline Österr. mit GL im Ausland & 149.740 & 4,2 & 72,4 & 5,4 & 11,9 & 3,5 & 2,6 \\
\hline EU-15 & 20.341 & 3,8 & 67,3 & 7,9 & 16,2 & 2,1 & 2,7 \\
\hline Deutschland & 15.097 & 3,7 & 67,9 & 8,0 & 15,6 & 2,2 & 2,7 \\
\hline „Gastarbeiter“6 & 48.551 & 4,7 & 76,4 & 3,8 & 7,0 & 5,9 & 2,2 \\
\hline Bosnien und Herzegowina & 7.875 & 4,9 & 75,1 & 2,3 & 7,4 & 8,4 & 1,9 \\
\hline Serbien u. Montenegro & 16.317 & 4,2 & 71,9 & 5,9 & 7,5 & 8,2 & 2,3 \\
\hline Kroatien & 4.553 & 2,7 & 71,3 & 5,4 & 13,6 & 5,2 & 1,9 \\
\hline Mazedonien & 1.418 & 6,0 & 73,6 & 2,5 & 7,8 & 7,5 & 2,5 \\
\hline Türkei & 16.769 & 5,7 & 83,5 & 1,8 & 3,9 & 2,8 & 2,3 \\
\hline Slowenien & 1.619 & 2,0 & 71,3 & 7,3 & 14,5 & 3,7 & 1,2 \\
\hline Višegrad und Rumänien & 47.320 & 2,3 & 72,2 & 6,8 & 13,7 & 2,5 & 2,4 \\
\hline Polen & 11.862 & 2,7 & 79,1 & 4,0 & 10,0 & 2,2 & 2,0 \\
\hline Rumänien & 5.525 & 4,2 & 69,1 & 5,6 & 15,2 & 3,1 & 2,9 \\
\hline Slowakei & 4.209 & 2,4 & 72,2 & 7,2 & 13,4 & 2,6 & 2,3 \\
\hline Tschechische Republik & 18.163 & 1,4 & 69,2 & 8,9 & 15,4 & 2,6 & 2,5 \\
\hline Ungarn & 7.561 & 2,4 & 71,1 & 7,1 & 14,7 & 2,3 & 2,4 \\
\hline Schweiz & 1.190 & 7,0 & 63,0 & 7,8 & 16,3 & 1,7 & 4,2 \\
\hline Vereinigte Staaten & 840 & 6,3 & 56,9 & 10,7 & 20,6 & 0,7 & 4,8 \\
\hline anderer Staat, unbekannt & 31.498 & 6,6 & 70,5 & 4,0 & 13,4 & 2,1 & 3,4 \\
\hline Nichtösterr. mit GL im Inland & 34.136 & 14,1 & 67,3 & 2,9 & 5,3 & 6,1 & 4,3 \\
\hline Nichtösterr. mit GL im Ausland & 205.792 & 15,3 & 62,2 & 3,0 & 7,3 & 6,4 & 5,8 \\
\hline EU-15 & 20.173 & 20,0 & 52,5 & 5,2 & 14,1 & 2,4 & 5,7 \\
\hline Deutschland & 10.473 & 19,1 & 54,7 & 5,5 & 13,5 & 2,2 & 5,0 \\
\hline „Gastarbeiter“ & 123.109 & 12,6 & 67,1 & 2,3 & 4,8 & 8,5 & 4,6 \\
\hline Bosnien und Herzegowina & 25.852 & 15,2 & 65,8 & 2,0 & 5,7 & 6,4 & 5,0 \\
\hline Serbien u. Montenegro & 55.543 & 11,2 & 64,4 & 2,6 & 4,6 & 13,1 & 4,0 \\
\hline Kroatien & 6.012 & 11,4 & 63,3 & 2,8 & 9,3 & 8,2 & 4,9 \\
\hline Mazedonien & 5.055 & 12,9 & 67,8 & 2,5 & 7,0 & 5,1 & 4,6 \\
\hline Türkei & 29.866 & 13,3 & 73,9 & 2,0 & 3,0 & 2,3 & 5,4 \\
\hline Slowenien & 781 & 11,1 & 59,5 & 3,8 & 10,2 & 10,4 & 4,9 \\
\hline Višegrad und Rumänien & 25.094 & 17,2 & 58,6 & 3,3 & 8,0 & 4,8 & 8,1 \\
\hline Polen & 12.430 & 17,6 & 61,3 & 2,6 & 5,8 & 4,2 & 8,6 \\
\hline Rumänien & 3.490 & 19,7 & 55,3 & 3,2 & 10,3 & 5,1 & 6,4 \\
\hline Slowakei & 2.979 & 16,4 & 56,8 & 3,7 & 7,2 & 7,4 & 8,5 \\
\hline Tschechische Republik & 2.238 & 13,7 & 56,9 & 5,2 & 11,7 & 6,1 & 6,5 \\
\hline Ungarn & 3.957 & 16,2 & 55,3 & 4,1 & 11,9 & 4,0 & 8,5 \\
\hline Schweiz & 1.118 & 17,4 & 53,3 & 6,6 & 14,0 & 3,0 & 5,6 \\
\hline Vereinigte Staaten & 2.078 & 20,2 & 49,5 & 6,7 & 14,0 & 2,3 & 7,3 \\
\hline anderer Staat, unbekannt & 34.220 & 20,5 & 54,3 & 3,3 & 11,2 & 2,6 & 8,1 \\
\hline
\end{tabular}

Quelle: Sonderauswertung von Statistik Austria, Volks-, Gebäude- und Wohnungszählung 2001, eigene Berechnungen. Anmerkung: GL = Geburtsland. 
gentümerquoten auf. Befristete Hauptmietverhältnisse stehen bei US-Amerikanern, EU-Bürgern und Rumänen hoch im Kurs und spiegeln den hohen Anteil an temporärer Migration wider. Mit jeweils rund 14\% sind Schweizer, US-Amerikaner und Deutsche unter den Nichteingebürgerten jene mit den meisten Wohnungseigentümern. Unter den Zuwanderern aus Ostmitteleuropa sind es am häufigsten die Ungarn und die Tschechen und am seltensten die Polen, die sich eine Eigentumswohnung angeschafft haben. Befristete Hauptmieten sind in allen Herkunftsgruppen der Višegrad-Kategorie häufiger als unter den „Gastarbeitern“. Bei den rumänischen Staatsbürgern sind Befristungen am häufigsten, bei Tschechen am seltensten. Unbefristete Hauptmietwohnungen erfreuen sich unter den Bürgern Polens der größten Beliebtheit.

Bei den Eingebürgerten tritt der Trend zum Eigentum verstärkt in Erscheinung. Dies gilt für alle Herkunftsländer, vor allem aber für Zuwanderer aus Deutschland, der Schweiz und den USA. Simultan mit der Einbürgerung manifestiert sich ein signifikanter Rückgang der befristeten Hauptmieten sowie der Dienstwohnungen quer über alle Herkunftsgruppen. Am häufigsten ist das Logieren in Dienstwohnungen bei eingebürgerten Bosniern und Mazedoniern. Wer sich hat einbürgern lassen, der weist eine langfristigere Aufenthaltsperspektive auf und ist daher auch eher bestrebt, eine Wohnung oder ein Haus käuflich zu erwerben. Deutlich manifestiert sich der Trend in Richtung Eigentum bei den eingebürgerten Polen. Krass tritt in dieser Herkunftsgruppe auch der Rückgang der Befristungen in Erscheinung. In der türkischen Herkunftsgruppe dominieren Mietverhältnisse, während der Hang zum Eigentum auch unter den Eingebürgerten schwach ist. Immerhin steigt der Anteil unbefristeter Hauptmieten bei den eingebürgerten Türken von $74 \%$ auf $84 \%$.

Während die Kategorie der Dienstwohnung unter eingebürgerten Kroaten und Serben seltener auftritt, ist sie bei eingebürgerten Bosniern recht häufig (8,4\%). Der progressive Trend zum Wohnungseigentum unter den Eingebürgerten tritt besonders bei den Kroaten hervor: 13,6\% besitzen Eigentumswohnungen. Der Hang zum Eigentum manifestiert sich auch in der serbischen Herkunftsgruppe. Befristete Hauptmieten stehen bei den Nichteingebürgerten höher im Kurs. Am deutlichsten manifestiert sich die Reduktion der befristeten Hauptmietverträge unter den eingebürgerten Immigranten aus Bosnien.

\subsubsection{Der Eigentümer des Gebäudes}

Dass ausländische Staatsbürger zu mehr als 70\% in Häusern privater Vermieter Fuß gefasst haben, veranschaulicht Tabelle 13. Analoges gilt auch für die zweite Generation. Die Verteilung der eingebürgerten Immigranten unterscheidet sich davon erheblich: Nur 47\% bewohnen Häuser im Eigentum von Privatpersonen, während nahezu ein Drittel im Gebäudebestand von Gebietskörperschaften logiert. Doppelt so hoch ist auch der Anteil in Wohnungen gemeinnütziger Bauvereinigungen. Die Verteilung der Eingebürgerten hat sich also jener der Inländer ohne Migrationshintergrund angenähert, wenngleich mit mehr als 17\% mehr Inländer als Eingebürgerte im Wohnbaubestand der „Gemeinnützigen“ zu finden sind. 
Tabelle 13: Personen in Privatwohnungen in Wien nach dem Eigentümer des Gebäudes, dem Geburtsland und der Staatsangehörigkeit 2001

\begin{tabular}{|c|c|c|c|c|c|}
\hline & insgesamt & $\begin{array}{r}\text { Privat- } \\
\text { per- } \\
\text { son/en }\end{array}$ & $\begin{array}{r}\text { Gebiets- } \\
\text { körper- } \\
\text { schaft }\end{array}$ & $\begin{array}{l}\text { Gemein- } \\
\text { nütz. Bau- } \\
\text { verein. }\end{array}$ & $\begin{array}{c}\text { sonstige } \\
\text { jurist. } \\
\text { Person }\end{array}$ \\
\hline Österr. ohne Migrationshinterg. & 1.127 .981 & 43,0 & 32,7 & 17,1 & 7,1 \\
\hline Österr. mit GL im Ausland & 149.740 & 47,0 & 32,6 & 12,6 & 7,7 \\
\hline EU-15 & 20.341 & 52,0 & 25,7 & 13,2 & 9,0 \\
\hline Deutschland & 15.097 & 50,6 & 26,9 & 13,9 & 8,6 \\
\hline „Gastarbeiter“ & 48.551 & 47,0 & 38,6 & 7,1 & 7,3 \\
\hline Bosnien und Herzegowina & 7.875 & 50,9 & 30,3 & 10,6 & 8,3 \\
\hline Serbien u. Montenegro & 16.317 & 47,9 & 37,2 & 7,8 & 7,1 \\
\hline Kroatien & 4.553 & 49,3 & 30,0 & 12,5 & 8,1 \\
\hline Mazedonien & 1.418 & 47,2 & 36,1 & 5,9 & 10,7 \\
\hline Türkei & 16.769 & 43,3 & 47,2 & 3,1 & 6,4 \\
\hline Slowenien & 1.619 & 48,9 & 31,5 & 11,4 & 8,2 \\
\hline Višegrad und Rumänien & 47.320 & 45,6 & 29,5 & 17,2 & 7,6 \\
\hline Polen & 11.862 & 39,2 & 29,7 & 23,7 & 7,4 \\
\hline Rumänien & 5.525 & 48,9 & 27,9 & 15,2 & 7,9 \\
\hline Slowakei & 4.209 & 41,6 & 33,5 & 17,7 & 7,2 \\
\hline Tschechische Republik & 18.163 & 48,5 & 29,9 & 14,7 & 7,0 \\
\hline Ungarn & 7.561 & 48,6 & 27,4 & 14,5 & 9,6 \\
\hline Schweiz & 1.190 & 57,9 & 16,2 & 14,1 & 11,8 \\
\hline Vereinigte Staaten & 840 & 67,0 & 10,7 & 10,8 & 11,4 \\
\hline anderer Staat, unbekannt & 31.498 & 44,9 & 33,8 & 13,8 & 7,5 \\
\hline Nichtösterr. mit GL im Inland & 34.136 & 74,7 & $\mathbf{8 , 0}$ & 5,8 & 11,4 \\
\hline Nichtösterr. mit GL im Ausland & 205.792 & 71,9 & 10,4 & 6,3 & 11,4 \\
\hline EU-15 & 20.173 & 71,6 & 7,9 & 7,3 & 13,2 \\
\hline Deutschland & 10.473 & 70,3 & 8,6 & 8,4 & 12,7 \\
\hline „Gastarbeiter“ & 123.109 & 75,4 & 9,4 & 4,1 & 11,1 \\
\hline Bosnien und Herzegowina & 25.852 & 74,3 & 6,1 & 7,5 & 12,1 \\
\hline Serbien u. Montenegro & 55.543 & 76,8 & 9,1 & 3,3 & 10,8 \\
\hline Kroatien & 6.012 & 72,1 & 8,6 & 7,0 & 12,2 \\
\hline Mazedonien & 5.055 & 76,1 & 9,8 & 2,4 & 11,7 \\
\hline Türkei & 29.866 & 74,5 & 12,9 & 2,4 & 10,3 \\
\hline Slowenien & 781 & 73,0 & 7,8 & 8,6 & 10,6 \\
\hline Višegrad und Rumänien & 25.094 & 65,4 & 12,0 & 11,7 & 10,9 \\
\hline Polen & 12.430 & 66,9 & 10,3 & 12,9 & 9,9 \\
\hline Rumänien & 3.490 & 65,6 & 14,2 & 9,1 & 11,2 \\
\hline Slowakei & 2.979 & 58,5 & 16,5 & 12,2 & 12,8 \\
\hline Tschechische Republik & 2.238 & 62,3 & 13,9 & 12,2 & 11,6 \\
\hline Ungarn & 3.957 & 67,3 & 11,2 & 9,8 & 11,8 \\
\hline Schweiz & 1.118 & 72,0 & 6,2 & 6,4 & 15,5 \\
\hline Vereinigte Staaten & 2.078 & 74,6 & 4,6 & 6,0 & 14,8 \\
\hline anderer Staat, unbekannt & 34.220 & 63,9 & 14,8 & 9,5 & 11,8 \\
\hline
\end{tabular}

Quelle: Sonderauswertung von Statistik Austria, Volks-, Gebäude- und Wohnungszählung 2001, eigene Berechnungen. Anmerkung: GL = Geburtsland. 
Tabelle 13 dokumentiert darüber hinaus gruppenbezogene Spezifika. Unter Ausländern ist ein Konzentrationsprozess von „Gastarbeitern“ wie auch Elitemigranten auf den privaten Wohnhausbestand zu konstatieren. Im Vergleich dazu ist das Wohnen im privaten Mietshaus unter den Ost-West-Migranten weniger populär. Am wenigsten (59\%) bewohnen die Slowaken Mietshäuser, bei den anderen Gruppen sind die Anteile etwas höher. Die „neue“ Migration zieht es stärker in den Hausbestand von Gebietskörperschaften und gemeinnützigen Bauvereinigungen. So sind fast $12 \%$ der Ost(mittel)europäer, aber nur 4\% der Türken und Exjugoslawen in Wohnblocks der „Gemeinnützigen“ ansässig.

Der Trend weg vom privaten Mietshaus hin zum Hausbestand der Gebietskörperschaften ist bei eingebürgerten Türken und Exjugoslawen stark. Mit über 47\% entfällt der höchste Anteil einer Herkunftsgruppe im kommunalen Wohnbau auf eingebürgerte Türken. Serben sind zu 37\% und Mazedonier zu 36\% ebenfalls im Baubestand der Gebietskörperschaften ansässig. Das genossenschaftliche Bestandssegment wird in einem viel höheren Ausmaß von eingebürgerten Ost-West-Migranten als von „Gastarbeitern" genutzt. Eingebürgerte Türken sind am seltensten im genossenschaftlichen Wohnbau zu finden. Im Gegensatz dazu leben vor allem aus Polen und der Slowakei stammende Neoösterreicher in Häusern der „Gemeinnützigen“. Die Mobilität aus dem privaten Mietshausbestand hat sich auch unter EU-Migranten vollzogen. Eingebürgerte Deutsche wohnten nur mehr zu rund $50 \%$ in Gebäuden in privatem Eigentum - ein um zwanzig Prozentpunkte niedrigerer Anteil als bei den deutschen Staatsbürgern. Zugleich hat sich der Anteil der im Gemeindebau wohnenden eingebürgerten Deutschen verdreifacht.

\subsubsection{Das Baualter des Gebäudes}

Das Baualter und die Gebäudeeigentümerschaft stehen in einem Zusammenhang. Kommunalwohnungen wurden erst seit der Ersten Republik errichtet, Genossenschaftswohnungen in größerem Umfang erst ab den 1950er Jahren. Das Wohnen im Gründerzeithaus ist ein vor allem unter den ehemaligen „Gastarbeitern“ verbreitetes Phänomen. Gründerzeithäuser werden in den bürgerlichen Wohnbezirken auch von Inländern und Elitemigranten genutzt. Abbildung 12 weist für die Inländer einen hohen Anteil (fast 29\%) des Wohnens in älteren Neubauten (1961-1980) nach. Etwa jeder vierte Wiener wohnt in einem vor 1919 errichteten Haus. Der Verteilung der Autochthonen auf die unterschiedlichen Baualtersklassen recht ähnlich ist jene der Eingebürgerten. Diese sind allerdings zu einem höheren Anteil im Altbau wohnhaft und weniger im Baubestand der Periode 1961-1980. Ähnlich sind einander die Verteilungen der Ausländer sowie der zweiten Generation. Bei den Ausländern waren fast $64 \%$ in Altbauten wohnhaft.

Das Wohnen im Gründerzeithaus ist kein für alle Herkunftsgruppen gleichermaßen typisches Phänomen (vgl. Tabelle 14). Unter den ausländischen Staatsbürgern sind es in erster Linie Serben, Türken und Mazedonier, die Altbauten bewohnen. 74\% der 
Tabelle 14: Personen in Privatwohnungen in Wien nach der Bauperiode, dem Geburtsland und der Staatsangehörigkeit 2001

\begin{tabular}{|c|c|c|c|c|c|c|c|}
\hline & insgesamt & $\begin{array}{r}\text { vor } \\
1919\end{array}$ & $\begin{array}{r}1919 \\
\text { bis } \\
1944 \\
\end{array}$ & $\begin{array}{r}1945 \\
\text { bis } \\
1960 \\
\end{array}$ & $\begin{array}{r}1961 \\
\text { bis } \\
1980 \\
\end{array}$ & $\begin{array}{r}1981 \\
\text { bis } \\
1990 \\
\end{array}$ & $\begin{array}{l}1991, \\
\text { spät., } \\
\text { n.rek. }\end{array}$ \\
\hline Österr. ohne Migrationshinterg. & 1.127 .981 & 25,7 & 11,1 & 12,5 & 28,9 & 11,1 & $\mathbf{1 0 , 7}$ \\
\hline Österr. mit GL im Ausland & 149.740 & 32,9 & 10,9 & 12,1 & 25,3 & 8,9 & 10,0 \\
\hline EU-15 & 20.341 & 31,6 & 9,2 & 12,7 & 31,0 & 8,4 & 7,1 \\
\hline Deutschland & 15.097 & 29,9 & 9,4 & 13,3 & 32,4 & 8,3 & 6,8 \\
\hline „Gastarbeiter“ & 48.551 & 40,4 & 13,6 & 12,4 & 20,0 & 6,4 & 7,1 \\
\hline Bosnien und Herzegowina & 7.875 & 44,7 & 11,5 & 10,1 & 16,7 & 5,9 & 11,0 \\
\hline Serbien und Montenegro & 16.317 & 38,1 & 14,0 & 13,1 & 21,2 & 6,4 & 7,1 \\
\hline Kroatien & 4.553 & 34,8 & 11,1 & 11,7 & 24,0 & 8,9 & 9,6 \\
\hline Mazedonien & 1.418 & 44,3 & 13,0 & 12,8 & 16,0 & 6,3 & 7,5 \\
\hline Türkei & 16.769 & 42,6 & 15,5 & 13,1 & 18,4 & 5,7 & 4,7 \\
\hline Slowenien & 1.619 & 32,2 & 9,2 & 11,4 & 31,6 & 8,6 & 6,9 \\
\hline Višegrad und Rumänien & 47.320 & 27,2 & 9,1 & 13,1 & 30,0 & 10,2 & 10,4 \\
\hline Polen & 11.862 & 26,9 & 8,6 & 9,5 & 20,5 & 16,3 & 18,2 \\
\hline Rumänien & 5.525 & 31,2 & 8,2 & 11,7 & 27,2 & 6,7 & 15,0 \\
\hline Slowakei & 4.209 & 22,1 & 8,7 & 15,0 & 33,5 & 10,3 & 10,3 \\
\hline Tschechische Republik & 18.163 & 26,0 & 9,5 & 16,0 & 36,1 & 7,6 & 4,8 \\
\hline Ungarn & 7.561 & 30,8 & 9,5 & 11,7 & 30,1 & 9,4 & 8,4 \\
\hline Schweiz & 1.190 & 41,5 & 7,1 & 9,2 & 22,0 & 9,7 & 10,3 \\
\hline Vereinigte Staaten & 840 & 41,4 & 6,8 & 8,7 & 23,5 & 8,1 & 11,5 \\
\hline anderer Staat, unbekannt & 31.498 & 30,0 & 10,7 & 9,8 & 23,0 & 11,0 & 15,6 \\
\hline Nichtösterr. mit GL im Inland & 34.136 & 71,0 & 6,3 & 5,8 & 9,1 & 2,2 & 5,6 \\
\hline Nichtösterr. mit GL im Ausland & 205.792 & 63,8 & 7,2 & 6,5 & 11,8 & 3,4 & 7,4 \\
\hline EU-15 & 20.173 & 49,6 & 6,7 & 7,3 & 17,9 & 6,8 & 11,6 \\
\hline Deutschland & 10.473 & 49,3 & 6,9 & 7,5 & 17,1 & 6,7 & 12,5 \\
\hline „Gastarbeiter“ & 123.109 & 74,1 & 7,0 & 5,6 & 7,3 & 1,7 & 4,3 \\
\hline Bosnien und Herzegowina & 25.852 & 71,2 & 6,0 & 5,1 & 8,1 & 1,6 & 8,0 \\
\hline Serbien u. Montenegro & 55.543 & 76,4 & 6,8 & 5,5 & 6,5 & 1,6 & 3,2 \\
\hline Kroatien & 6.012 & 63,8 & 6,7 & 7,1 & 11,4 & 3,1 & 8,0 \\
\hline Mazedonien & 5.055 & 74,2 & 7,0 & 6,2 & 7,3 & 1,2 & 4,1 \\
\hline Türkei & 29.866 & 75,0 & 8,3 & 5,7 & 7,0 & 1,5 & 2,5 \\
\hline Slowenien & 781 & 53,3 & 5,4 & 7,9 & 17,3 & 7,2 & 9,0 \\
\hline Višegrad und Rumänien & 25.094 & 50,0 & 7,4 & 7,5 & 16,6 & 5,2 & 13,2 \\
\hline Polen & 12.430 & 55,7 & 7,0 & 6,4 & 12,6 & 4,5 & 13,7 \\
\hline Rumänien & 3.490 & 48,5 & 9,2 & 8,9 & 18,3 & 4,9 & 10,3 \\
\hline Slowakei & 2.979 & 42,4 & 7,6 & 8,2 & 19,6 & 5,9 & 16,3 \\
\hline Tschechische Republik & 2.238 & 42,4 & 7,1 & 8,8 & 21,9 & 6,4 & 13,4 \\
\hline Ungarn & 3.957 & 43,7 & 7,3 & 8,6 & 22,3 & 6,1 & 12,0 \\
\hline Schweiz & 1.118 & 54,6 & 8,2 & 6,1 & 16,2 & 5,6 & 9,3 \\
\hline Vereinigte Staaten & 2.078 & 50,9 & 5,7 & 7,4 & 20,6 & 5,9 & 9,6 \\
\hline anderer Staat, unbekannt & 34.220 & 46,2 & 8,0 & 8,4 & 20,1 & 5,9 & 11,4 \\
\hline
\end{tabular}

Quelle: Sonderauswertung von Statistik Austria, Volks-, Gebäude und Wohnungszählung 2001, eigene Berechnungen. Anmerkung: GL = Geburtsland. 
„Gastarbeiter“ verfügten 2001 über Wohnungen im Gründerzeitbestand. Unter Višegrad-Zuwanderern und EU-15-Migranten lag der Anteil bei knapp der Hälfte. Die Verteilungen von nichteingebürgerten Ost-West- und EU-Migranten auf die Baualtersklassen sind einander sehr ähnlich. Bei beiden Gruppen besteht darüber hinaus eine weitere Konzentration in Bauten der Errichtungsperiode 1961-1980.

Bei den Eingebürgerten aller Herkunftsgruppen schwächt sich die Konzentration auf den gründerzeitlichen Baubestand ab. Der Trend zum Wegzug aus dem Altbau ist bei Deutschen wie unter „Gastarbeitern“ gleichermaßen zu beobachten. Ein Fünftel der eingebürgerten „Gastarbeiter“ ist im Wohnbaubestand der Errichtungsperiode 1961-1980 zu finden, jeweils mehr als ein Zehntel in Zwischen- und Nachkriegszeithäusern. Österreicher mazedonischer Herkunft logieren nach wie vor am öftesten in Gründerzeithäusern, eingebürgerte Slowenen am seltensten. Unter eingebürgerten Schweizern und US-Amerikanern besteht eine nahezu analog hohe Wohnkonzentration im Altbaubestand wie bei den eingebürgerten Mazedoniern. Neoösterreicher aus Ost(mittel)europa haben den Altbaubestand bereits in einem hohen Ausmaß verlassen. Am häufigsten im Gründerzeitbau ansässig sind aus Rumänien stammende Österreicher, am seltensten die eingebürgerten Slowaken. Diese und eingebürgerte Tschechen sind oft in der Baualtersklasse 1961-1980 zu finden. Der Anteil der in Gründerzeithäusern wohnhaften Polen ist bei Eingebürgerten nur halb so hoch wie bei polnischen Staatsbürgern. Neoösterreicher polnischer Abstammung sind stark in den neueren Wohnbaubestand vorgedrungen. Eingebürgerte Polen sind jene Herkunftsgruppe, die am öftesten in nach 1991 errichteten Neubauten wohnhaft ist und dies sogar häufiger als Österreicher ohne Migrationshintergrund.

\subsubsection{Nutzfläche pro Person}

Die folgenden Analysen zur Wohnnutzfläche spiegeln die Benachteiligung der „Gastarbeiter“ sowie die privilegierte Positionierung der Oberschichtmigration aus der EU wider. Die Diskriminierung der „Gastarbeiter“ hinsichtlich der Wohnflächen kann zwar auch durch die Einbürgerung nicht völlig neutralisiert werden, schwächt sich aber ab (vgl. Tabelle 15).

Der Vergleich dokumentiert die Besserstellung der Österreicher ohne Migrationshintergrund. Von diesen mussten sich bloß 5,3\% mit einer Wohnfläche von bis zu 14 $\mathrm{m}^{2}$ bescheiden, bei der ausländischen Wohnbevölkerung galt dies für mehr als $34 \%$. Die zweite Generation ist schlechter gestellt als die Eingebürgerten, aber auch gegenüber den ausländischen Staatsbürgern im Nachteil. Türken und Exjugoslawen erweisen sich als besonders benachteiligt. Fast 60\% (!) der türkischen Staatsbürger und rund $52 \%$ der Mazedonier müssen mit höchstens $14 \mathrm{~m}^{2}$ pro Person das Auslangen finden. In der Wohnflächenklasse von $60 \mathrm{~m}^{2}$ und mehr finden sich nur 1,4\% Türken und 2,2\% Mazedonier. Kontradiktorisch dazu positionieren sich EU-Zuwanderer. Die Zuwanderung aus Ost(mittel)europa rangiert zwischen diesen beiden Polen, wobei die Rumänen die schlechteste Wohnflächenversorgung aufweisen. 
Tabelle 15: Personen in Privatwohnungen in Wien nach der Nutzfläche in $\mathbf{m}^{\mathbf{2}}$ pro Person, dem Geburtsland und der Staatsangehörigkeit 2001

\begin{tabular}{|c|c|c|c|c|c|c|}
\hline & insgesamt & $\begin{array}{r}\text { bis } 14 \\
\mathrm{~m}^{2}\end{array}$ & $\begin{array}{l}15 \text { bis } \\
24 \mathrm{~m}^{2}\end{array}$ & $\begin{array}{l}25 \text { bis } \\
39 \mathrm{~m}^{2}\end{array}$ & $\begin{array}{l}40 \mathrm{bis} \\
59 \mathrm{~m}^{2}\end{array}$ & $\begin{array}{l}60 \text { und } \\
\text { mehr m }\end{array}$ \\
\hline Österr. ohne Migrationshinterg. & 1.127 .981 & 5,3 & 22,6 & 36,0 & 21,0 & 15,0 \\
\hline Österr. mit GL im Ausland & 149.740 & 14,7 & 26,9 & 29,3 & 16,8 & 12,3 \\
\hline EU-15 & 20.341 & 2,4 & 13,6 & 33,7 & 26,5 & 23,8 \\
\hline Deutschland & 15.097 & 2,2 & 12,6 & 33,4 & 27,1 & 24,8 \\
\hline „Gastarbeiter“ & 48.551 & 29,1 & 34,8 & 21,7 & 9,3 & 5,1 \\
\hline Bosnien und Herzegowina & 7.875 & 21,7 & 42,9 & 24,0 & 8,1 & 3,3 \\
\hline Serbien und Montenegro & 16.317 & 21,5 & 32,4 & 26,6 & 12,5 & 6,9 \\
\hline Kroatien & 4.553 & 8,9 & 29,8 & 34,4 & 17,0 & 9,8 \\
\hline Mazedonien & 1.418 & 33,6 & 39,0 & 16,9 & 7,5 & 3,0 \\
\hline Türkei & 16.769 & 47,5 & 35,7 & 11,5 & 3,5 & 1,8 \\
\hline Slowenien & 1.619 & 4,5 & 19,4 & 34,3 & 24,2 & 17,7 \\
\hline Višegrad und Rumänien & 47.320 & 3,4 & 19,3 & 36,0 & 23,3 & 18,0 \\
\hline Polen & 11.862 & 4,1 & 26,7 & 37,6 & 19,1 & 12,5 \\
\hline Rumänien & 5.525 & 9,0 & 27,2 & 33,0 & 18,2 & 12,6 \\
\hline Slowakei & 4.209 & 3,0 & 18,4 & 37,4 & 23,9 & 17,3 \\
\hline Tschechische Republik & 18.163 & 1,3 & 12,4 & 35,8 & 27,3 & 23,3 \\
\hline Ungarn & 7.561 & 3,4 & 19,1 & 35,6 & 23,9 & 18,0 \\
\hline Schweiz & 1.190 & 3,4 & 17,4 & 31,1 & 25,4 & 22,7 \\
\hline Vereinigte Staaten & 840 & 7,5 & 16,7 & 33,1 & 23,2 & 19,5 \\
\hline anderer Staat, unbekannt & 31.498 & 17,8 & 35,6 & 27,9 & 11,8 & 7,0 \\
\hline Nichtösterr. mit GL im Inland & 34.136 & 55,6 & 29,7 & 9,7 & 3,2 & 1,8 \\
\hline Nichtösterr. mit GL im Ausland & 205.792 & 34,6 & 31,8 & 19,5 & 8,7 & $\mathbf{5 , 3}$ \\
\hline EU-15 & 20.173 & 5,0 & 17,0 & 33,2 & 24,7 & 20,2 \\
\hline Deutschland & 10.473 & 4,4 & 16,1 & 32,5 & 25,3 & 21,6 \\
\hline „Gastarbeiter“ & 123.109 & 45,6 & 34,0 & 14,0 & 4,4 & 2,0 \\
\hline Bosnien und Herzegowina & 25.852 & 41,6 & 39,4 & 14,0 & 3,7 & 1,3 \\
\hline Serbien u. Montenegro & 55.543 & 41,4 & 36,2 & 15,4 & 4,8 & 2,3 \\
\hline Kroatien & 6.012 & 29,2 & 38,2 & 21,5 & 7,3 & 3,9 \\
\hline Mazedonien & 5.055 & 51,9 & 29,4 & 12,4 & 4,1 & 2,2 \\
\hline Türkei & 29.866 & 59,6 & 25,4 & 9,8 & 3,7 & 1,4 \\
\hline Slowenien & 781 & 22,4 & 30,1 & 27,9 & 11,3 & 8,3 \\
\hline Višegrad und Rumänien & 25.094 & 18,2 & 34,6 & 29,0 & 11,9 & 6,3 \\
\hline Polen & 12.430 & 18,8 & 36,3 & 28,2 & 11,2 & 5,4 \\
\hline Rumänien & 3.490 & 23,1 & 36,5 & 26,6 & 8,8 & 5,0 \\
\hline Slowakei & 2.979 & 17,8 & 32,5 & 30,2 & 12,5 & 7,0 \\
\hline Tschechische Republik & 2.238 & 10,1 & 31,2 & 32,0 & 16,1 & 10,5 \\
\hline Ungarn & 3.957 & 16,9 & 30,7 & 31,0 & 14,1 & 7,3 \\
\hline Schweiz & 1.118 & 3,8 & 13,7 & 30,1 & 26,3 & 26,1 \\
\hline Vereinigte Staaten & 2.078 & 6,0 & 15,4 & 28,7 & 26,4 & 23,5 \\
\hline anderer Staat, unbekannt & 34.220 & 27,5 & 32,2 & 23,7 & 10,6 & 6,0 \\
\hline
\end{tabular}

Quelle: Sonderauswertung von Statistik Austria, Volks-, Gebäude und Wohnungszählung 2001, eigene Berechnungen. Anmerkung: GL = Geburtsland. 
Welche Veränderungen erfolgen in der Kategorie der Eingebürgerten? Die Wohnflächenversorgung ist fast über alle Gruppen hinweg besser, allerdings in divergierendem Ausmaß. Am wenigsten bei den US-Amerikanern und Schweizern, deren eingebürgerte Landsleute in den größten Wohnflächenklassen sogar etwas schwächer repräsentiert sind als die Nichteingebürgerten. Die Zunahme der Wohnfläche bei den Eingebürgerten ist bei den diesbezüglich gut versorgten Deutschen in erster Linie in den größten Wohnflächenkategorien ab $40 \mathrm{~m}^{2}$ zu verzeichnen. Eingebürgerte Türken und Mazedonier sind zwar nach wie vor flächenmäßig am prekärsten versorgt, es manifestiert sich aber auch bei ihnen ein Trend in Richtung einer Verbesserung in Form einer Wohnflächenausweitung in den Größenklassen 15 bis 24 sowie 25 bis $39 \mathrm{~m}^{2}$. Bei eingebürgerten Kroaten beläuft sich der Anteil in der kleinsten Wohnflächenklasse auf rund 9\% gegenüber 29\% unter den kroatischen Staatsbürgern. Eine eklatante Verbesserung der Flächenversorgung liegt im Fall der naturalisierten Ost-West-Migranten vor. Bei diesen geht die Tendenz in Richtung der größten Wohnflächenkategorien. In der tschechischen Herkunftsgruppe ist der Anteil der Eingebürgerten, die über $40 \mathrm{~m}^{2}$ zur Verfügung haben, sogar höher als bei den Schweizern. Die Verbesserung der Wohnflächenversorgung der eingebürgerten Polen bezieht sich auf alle Nutzflächengrößenklassen.

Die Befunde aus der Auswertung der amtlichen Daten sprechen also eine eindeutige Sprache: Ungeachtet aller Variationen verfügen die eingebürgerten Zuwanderer im Durchschnitt über mehr Wohnfläche und über Wohneinheiten, die standardmäßig zum Teil erheblich besser ausgestattet sind. Es ist auch ein Mobilitätstrend vom privaten Mietwohnungssektor in Richtung auf Kommunal- und Genossenschaftswohnungen sowie aus dem gründerzeitlichen Altbau in neuere Baubestandssegmente nachweisbar.

\subsection{Aufenthaltsdauer oder Einbürgerung: Welcher Faktor ist relevanter?}

Die in den vorhergehenden Abschnitten gebotenen Analysen basieren auf Volks-, Häuser- und Wohnungszählung. Eine auf dieser Grundlage nicht beantwortbare Frage ist jene nach den Auswirkungen der Aufenthaltsdauer, da diese Variable in der Volkszählung nicht erhoben wird. Es ist also nicht gänzlich auszuschließen, dass der in den vorangegangenen Analysen auftretende Einbürgerungseffekt eigentlich eine Funktion der Aufenthaltsdauer darstellt. Die geeignete Datengrundlage zur Klärung bietet hier der Mikrozensus. Dieser beinhaltet die Variable der Aufenthaltsdauer.

Die nun folgende Analyse soll dazu dienen, den Effekt der Einbürgerung auf die Wohnsituation unter Kontrolle der Variablen der Aufenthaltsdauer zu untersuchen. Sollte die Einbürgerung für die Wohnintegration tatsächlich eine Rolle spielen, dann müssten auch nach dem Zeitpunkt der Ankunft Unterschiede zwischen eingebürgerten und nichteingebürgerten Migranten bestehen. Oder anders formuliert: Ist die Einbürgerung irrelevant, so wären keine Unterschiede feststellbar.

Dass zwischen der Aufenthaltsdauer und der Einbürgerung ein enger Konnex besteht, erklärt sich schon aus dem formalen Faktum, dass in allen europäischen Staaten 
eine jeweils bestimmte Aufenthaltsdauer die Voraussetzung für eine Einbürgerung darstellt. Da ein erheblicher Teil der in Wien lebenden Migranten selbst nach einem sehr langen Aufenthalt den Schritt zur Einbürgerung nicht gesetzt hat, ist auch die Frage nach den Ursachen dieser „Einbürgerungsresistenz" interessant. Diese Frage wird - zumindest zum Teil - in den halbstandardisierten Interviews beantwortet.

Tabelle 16: Bevölkerung in Wien nach dem Migrationshintergrund 2005

\begin{tabular}{lrrrr}
\hline Kategorie & Staatsbürgerschaft & Geburtsland & abs. & in \% \\
\hline Inländer ohne Migrationshinterg. & Österreich & Österreich & 1.126 .180 & 69,5 \\
Zuwanderer & Ausland & Ausland & 253.801 & 15,6 \\
Neoösterreicher (Eingebürgerte, & Österreich & Ausland & 198.450 & 12,2 \\
Inländer mit Migrationshinterg. & & & & \\
Zweite Generation & Ausland & Österreich & 42.519 & 2,6 \\
insgesamt & & & 1.620 .949 & 100,0 \\
\hline
\end{tabular}

Quelle: Mikrozensus 4/05, eigene Berechnungen.

Tabelle 16 beinhaltet die Grundstruktur der Wiener Bevölkerung auf der Basis des MZ 4/05 und zeigt, dass alle Gruppen mit Migrationshintergrund auf dieser Datengrundlage etwas größer sind als in der Volkszählung. Bezüglich der Aufenthaltsdauer der Ausländer und der eingebürgerten Zuwanderer (aber nicht der zweiten Generation) zeigt Tabelle 17, dass etwas mehr als die Hälfte der Zugewanderten eine Aufenthaltsdauer von weniger als 16 Jahren aufweist. Es besteht ein Zusammenhang zwischen der Einbürgerung und der Aufenthaltsdauer: Mehr als die Hälfte der Eingebürgerten ist seit über 20 Jahren in Wien ansässig, nur ein Zehntel weniger als zehn Jahre. Umgekehrt verhält es sich bei den nichteingebürgerten Migranten: Mehr als die Hälfte ist kürzer als zehn Jahre in Wien ansässig und 16\% mehr als 20 Jahre. Leider werden auch im Mikrozensus die Beweggründe, die zur Einbürgerung führten, nicht erhoben.

Tabelle 17: Zugewanderte Bevölkerung in Wien nach der Aufenthaltsdauer

\begin{tabular}{lrr}
\hline & absolut & in $\%$ \\
\hline bis 5 Jahre & 93.132 & 20,6 \\
6 bis 10 Jahre & 61.774 & 13,7 \\
11 bis 15 Jahre & 84.710 & 18,7 \\
16 bis 25 Jahre & 95.258 & 21,1 \\
26 bis 35 Jahre & 60.964 & 13,5 \\
36 bis 45 Jahre & 25.082 & 5,5 \\
mehr als 45 Jahre & 31.330 & 6,9 \\
insgesamt & 452.250 & 100,0 \\
\hline
\end{tabular}

Quelle: Mikrozensus 4/05, eigene Berechnungen. 
Abbildung 1: Aufenthaltsdauer und Einbürgerungsquoten 2005

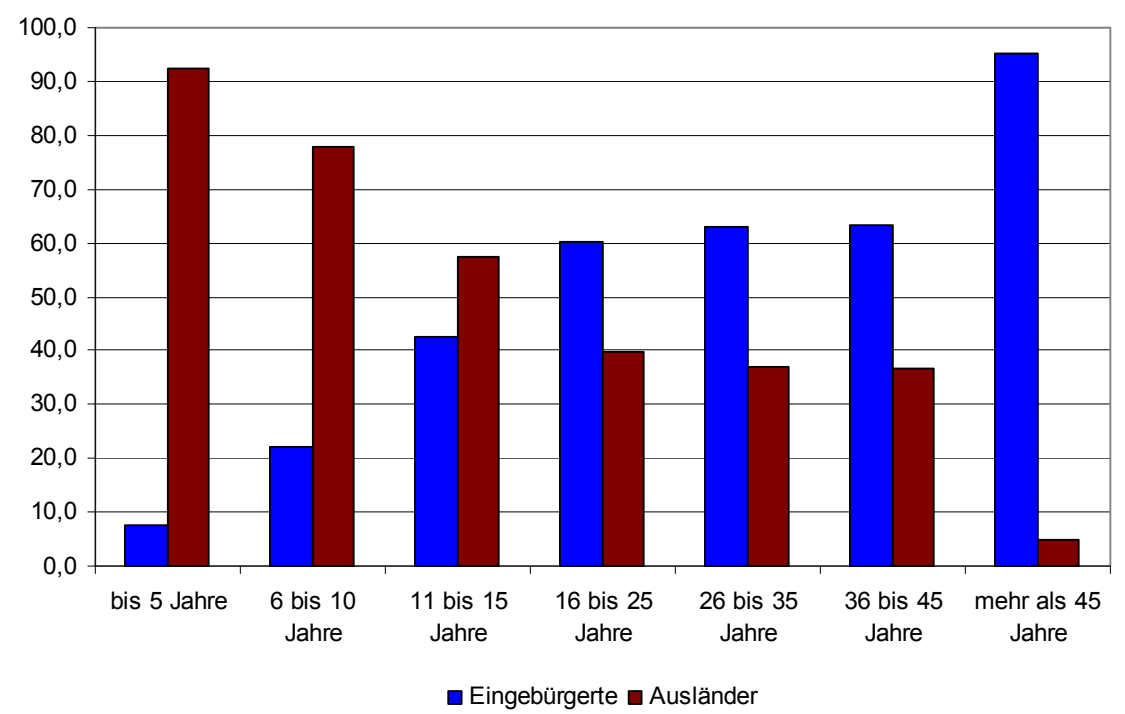

Quelle: Mikrozensus 4/05, eigene Berechnungen. Anmerkung: Bei Zellenbesätzen unter 20.000 Personen beträgt der Stichprobenfehler im Mikrozensus mehr als 20\%.

Abbildung 1 verdeutlicht den Konnex zwischen Aufenthaltsdauer und Einbürgerung. Während bei einer Aufenthaltsdauer bis 5 Jahre noch mehr als 90\% der Immigranten ihre ausländische Staatszugehörigkeit innehaben, ist es bei bereits über 45 jährigem Aufenthalt umgekehrt. In den Kategorien von 11 bis 15 Jahren sowie 16 bis 25 Jahren Aufenthalt kommt es zu starken Anstiegen bei den Eingebürgerten.

Die im Folgenden zu beantwortende Frage lautet: Welche Unterschiede bestehen zwischen Eingebürgerten und Nichteingebürgerten hinsichtlich der Wohnsituation unter Berücksichtigung der Aufenthaltsdauer? Für die weiteren Analysen wird daher eine Kategorisierung nach der Aufenthaltsdauer vorgenommen:

1. Aufenthaltsdauer bis 10 Jahre: 155.000 Personen, 13,5\% bereits eingebürgert, $86,5 \%$ mit ausländischer Staatsbürgerschaft;

2. Aufenthaltsdauer 11 bis 20 Jahre: 154.000 Personen, 49\% eingebürgert, $51 \%$ mit ausländischer Staatsbürgerschaft;

3. Aufenthaltsdauer mehr als 20 Jahre: 143.000 Personen 71,1\% eingebürgert, 28,9\% mit ausländischer Staatsbürgerschaft.

Tabelle 18 zeigt, dass sich der Faktor der Einbürgerung umso stärker positiv auf die Wohnqualität auswirkt, je länger die Betreffenden in Wien leben. In der Gruppe, die sich kürzer als 11 Jahre in Wien aufhält, sind die Unterschiede noch gering. Bei einer Aufenthaltsdauer von 11 bis 20 Jahren logieren bereits $87 \%$ der Eingebürgerten in Kategorie-A-Wohnungen (Nichteingebürgerte: 72\%). Am eklatantesten treten die Unterschiede bei über 20-jährigem Aufenthalt zu Tage. 
Tabelle 18: Zuwanderer nach Wohnstandardkategorie, Aufenthaltsdauer und Einbürgerungsstatus

\begin{tabular}{lrrr}
\hline & Kategorie A & A in \% & insg. \\
\hline bis 10 Jahre, eingebürgert & 16.237 & 77,7 & 20.887 \\
bis 10 Jahre, nichteingebürgert & 107.533 & 80,2 & 134.020 \\
11 bis 20 Jahre, eingebürgert & 65.753 & 87,0 & 75.537 \\
11 bis 20 Jahre, nichteingeb. & 56.534 & 72,1 & 78.369 \\
mehr als 20 Jahre, eingebürgert & 89.588 & 87,8 & 102.026 \\
mehr als 20 Jahre, nichteingeb. & 26.052 & 62,9 & 41.411 \\
insgesamt & 361.697 & 80,0 & 452.250 \\
\hline
\end{tabular}

Quelle: Mikrozensus 4/05, eigene Berechnungen.

Von der Wiener Gesamtbevölkerung lebten laut Mikrozensus 04/2005 9\% im Haus- und 12,4\% im Wohnungseigentum, fast drei Viertel der Wohnbevölkerung wohnten zur Miete. Hinsichtlich der einzelnen Wohnungsmarktsegmente waren die Unterschiede stark ausgeprägt (vgl. Tabelle 19): Eingebürgerte wohnten doppelt so oft im Eigentum und in Gemeindewohnungen, dafür seltener in Hauptmietwohnungen und auf Basis von sonstigen Rechtsverhältnissen als Nichteingebürgerte. Es zeigt sich also, dass die Einbürgerung eine Rolle spielt und die Verteilung auf die Wohnungsmarktsegmente nicht nur von der Aufenthaltsdauer abhängig ist. Ab einer Aufenthaltsdauer, welche den Zugang zur österreichischen Staatsbürgerschaft möglich macht (11 und mehr Jahre), leben nicht nur viel mehr eingebürgerte Migranten in Kommunalwohnungen, sondern auch im Eigentum. Wer sich bereits mehr als 20 Jahre im Land aufhält und sich einbürgern ließ, hat zu fast $26 \%$ eine Gemeindewohnung. Unter den Nichteingebürgerten mit analoger Aufenthaltsdauer ist der Anteilswert nicht einmal halb so hoch.

Tabelle 19: Subgruppen der Wohnbevölkerung nach dem Rechtsverhältnis der Wohnung

\begin{tabular}{lrrrr}
\hline & insgesamt & Österreicher & Eingebürgerte & Ausländer \\
\hline Eigentum Haus, Wohnung & 21,4 & 25,6 & 16,1 & 7,6 \\
Hauptmiete & 35,4 & 29,0 & 38,6 & 58,7 \\
Genossenschaft & 15,8 & 17,8 & 13,3 & 9,0 \\
Gemeindewohnung & 22,1 & 23,6 & 27,1 & 13,4 \\
sonstige & 5,4 & 4,1 & $(4,9)$ & 11,3 \\
insgesamt & 100,0 & 100,0 & 100,0 & 100,0 \\
insgesamt abs. & 1.620 .949 & 1.126 .180 & 198.450 & 253.801 \\
\hline
\end{tabular}

Quelle: Mikrozensus 4/05, eigene Berechnungen.

Worin liegt nun der grundlegende Unterschied? Wichtig ist die Rückkehr- bzw. Bleibeorientierung. Wer sich auch nach einem langen Aufenthalt in Wien nicht ein- 
bürgern lässt, bleibt eher in seiner billigen Substandardwohnung und spart das Geld für eine etwaige Rückkehr ins Herkunftsland. Sich einbürgern zu lassen impliziert auch die Absicht, in Österreich bleiben zu wollen und größere Investitionen in die Wohnqualität zu tätigen.

\subsection{Wohnintegration, Wohnmobilität und Einbürgerung im Spiegel der narrativen Interviews}

Zusätzlich zu den amtlichen Daten bildeten 11 halbstandardisierte Interviews sowie ein Experteninterview ${ }^{12}$ einen wichtigen Zugang zur Lebensrealität der Migranten. Es wurden dabei nach dem ,Schneeballsystem“ eingebürgerte und nichteingebürgerte Migranten unterschiedlichster Herkunftsländer mit mindestens fünfjähriger Aufenthaltsdauer in Österreich nach ihrer Wohnbiographie befragt.

Die auf den amtlichen Daten basierenden Resultate finden in den Interviews ihre Bestätigung, wenngleich das Gros der Befragten keinen direkten Konnex zwischen Einbürgerung und Wohnen herstellt. Die Wohnbiographien spiegeln eine Entwicklung hin zu einer Verbesserung der Wohnsituation wider. Jeder Wohnungswechsel ist nach Möglichkeit mit einer Verbesserung verbunden, bezogen auf die Wohnfläche, die Wohnungsausstattung, das Wohnumfeld etc. Wohnbiographien verlaufen aber nicht immer geradlinig. Bei erzwungenen Wohnungswechseln kann es temporär auch zu Verschlechterungen kommen, indem man etwa bei Verwandten oder in Notquartieren unterkommt.

Die Interviews dokumentieren einmal mehr die häufig extrem prekäre Wohnsituation vieler Migranten vor allem in der Anfangsphase ihres Aufenthaltes in Österreich, wobei Türken von schlechten Wohnstandards besonders betroffen sind:

R3: ,....sehr kleine Wohnung gehabt. Nur Kabinett und Küche ... Und es war also letzte Stock auf Hofseite und die Wohnung war schimmelig und ich war krank und ich habe Lungenentzündung gekriegt und Tuberkulose. ... Ja, aber Fenster, weil es war Hofseite, wenn es regnet ... dann Bank war ganz nass, feucht und durch das ist es schnell feucht geworden. " (Türkin, 45 Jahre, eingebürgert)

R7: ,Wieder Doppeltwohnung ohne Wasser, ohne nix, nur kalte Wasser. Und dann hamma zwei Wohnunge gehabt, ohne einen Platz zum Baden, nix ohne warme Wasser, wirklich nix, nur kalte Wasser" (Polin, 68 Jahre, nichteingebürgert)

Die Einbürgerung vollzieht sich in einem Spannungsfeld von rationalen Entscheidungskriterien und emotionalen Befindlichkeiten. Die Einbürgerung wird von den Zuwanderern vor allem als eine (bis Ende 2005 geltende) Voraussetzung zum Erwerb

12 Durchgeführt von Frau Mag. Josepha Stagl in den Monaten Juni bis August 2007. 
einer Gemeindewohnung betrachtet. Ansonsten haften der österreichischen Staatsbürgerschaft eher zweckrationale Motive an, die mehr in einem Konnex zu Arbeitsmarktchancen stehen als zur Wohnsituation. Die Aufgabe der Staatsbürgerschaft des Herkunftslandes kann hierbei als schmerzlich erlebt werden:

R3: „Ja, es war nicht einfach für mich, ich mein', das hat schon am Anfang ein bissl weh getan, weil da musste ich von der Türkei austreten, aber jetzt geht es wieder. " (Türkin, 45 Jahre, eingebürgert)

Die Aufenthaltsdauer als wesentliche Voraussetzung für die Einbürgerung ist auch eine wichtige Determinante der Wohnmobilität:

I: „, Spielt die Aufenthaltsdauer, die du in Österreich bist, für den Verlauf der Wohnkarriere eine Rolle? “ R1: „Ja schon, ... also wichtigste Rolle! “ (Georgier, 33 Jahre, nichteingebürgert)

E.: ,,... erst dann haben sie langsam geschaut, bleib’ ich jetzt da, aha, ich bleib' jetzt da. Hab' Enkelkinder, Kinder sind groß, ich kann doch nicht runter, weil die eigenen Verwandten sind auch verstorben und sie sich auch entschieden haben, hier zu bleiben, ... und sie jetzt auch Gemeindewohnungen jetzt in Anspruch nehmen. “ I.: „, Das heißt, erst dann haben sie sich entschieden, eine Gemeindewohnung zu nehmen?" E.: „Ja, ja! “ (Expertin, Gebietsbetreuung, türkischer Migrationshintergrund)

Die meisten Befragten stellen keinen Konnex zwischen der Wohnsituation und der Einbürgerung her. Die Veränderung der Wohnsituation wird in keinem Interview als zentraler Stimulus für den Erwerb der österreichischen Staatsbürgerschaft angeführt:

I.: „Und durch die Staatsbürgerschaft hat sich irgendwas an Ihrer Wohnsituation verändert? “ R3: „Nein, ich wollte nicht. Ich könnte in Gemeinde anmelden, so aber ich wollte nicht, .... “ I.: „Also für die Wohnsituation, also Sie haben nicht die Staatsbürgerschaft angenommen wegen der Wohnsituation?“ R3: „Nein, nein!“ (Türkin, 45 Jahre, eingebürgert)

I.: „, Glauben Sie, dass zum Beispiel Leute, die sich einbürgern lassen,..., dass die mehr Chancen auf eine bessere Wohnung haben?" R4:

„Nein, glaub' ich net. ... Hauptsache du arbeitest, aber dass du jetzt ein Staatsbürgerschaft nimmst und dann gleich eine Wohnung kriegst, geht auch nicht. " (Bosnierin, 44 Jahre, nichteingebürgert)

Die Positionierung vieler Migranten auf dem Wiener Wohnungsmarkt hat sich allerdings im Verlauf der beiden vergangenen Dekaden merklich verbessert:

I.: „Hast du das Gefühl, umso länger die Migranten in Österreich sind, umso besser werden die Wohnungen oder ist da immer der Standard sozusagen gleich?“ E.: „Es verbessert sich schon, also auch die Rahmenbedingungen verbessern sich ..." (Expertin, Gebietsbetreuung, türkischer Migrationshintergrund)

Die Wohnbiographie der meisten Migranten spiegelt also eine aufwärts gerichtete Wohnmobilität wider. Im Falle eines Wohnungswechsels liegt das Bestreben zugrun- 
de, die Wohn- und/oder Wohnumfeldqualität in entscheidenden Aspekten zu verbessern. Dies gelingt in der Realität allerdings nicht immer:

I: ,, Und jetzt geht es um das Wohnumfeld, ... das heisst, jedes Mal wenn Sie umgezogen sind, haben Sie das Gefühl gehabt, Sie ziehen immer in eine bessere Wohnung oder war das ... “. R2: ,Ja, ja, bessere und größere Wohnung. " (Kroatin, 44 Jahre, nichteingebürgert)

I.: „Hast du das Gefühl, dass du mit dieser Übersiedelung in den 16. Bezirk in eine bessere oder schlechtere Wohngegend übersiedelst oder gleichwertig? “ R1: „Ich glaub' schon bessere. ... “(Georgier, 33 Jahre, nichteingebürgert)

Im Spannungsfeld der Entscheidung pro oder kontra Einbürgerung werden vor allem zweckrationale Motive angeführt. Sie bedeutet für viele Migranten lediglich eine Erleichterung der Bewältigung des Alltags durch den Wegfall von Formalismen und bürokratischer Hürden sowie die Reduzierung der mühsamen Kontakte mit Ämtern. Die individuelle „Verwertbarkeit“ der Staatsbürgerschaft liegt vor allem in der Positionierung auf dem Arbeitsmarkt:

R3: „Eigentlich hab' ich's ja nicht gebraucht die österreichische Staatsbürgerschaft, aber es wäre nicht schlecht und na da brauch' ich 's nicht immer wieder Visum holen und solche Sachen, ja aber sonst ... " (Türkin, 45 Jahre, eingebürgert)

R6: , Wenn man die Staatsbürgerschaft hat, dann immer wenn man einen Job suchen will, dann ist es relativ leichter ... relativ wieder ... Ja, halt wegen Arbeitsmarkt ist es relativ einfacher, einen Job zu bekommen, also Staatsbürger zu sein, als jemand der halt nur Arbeitserlaubnis hat. " (Syrer, 39 Jahre, eingebürgert)

In einigen Fällen spielt der mit dem Staatsbürgerschaftserwerb verbundene finanzielle Aufwand eine demotivierende Rolle:

R2: „Das kostet viel Geld zum erst und zweitest ich hab' alles. Ich hab' Visum, ich hab' Arbeitserlaubnis und ich weiß es nicht warum, aber kostet viel Geld und ich glaub', ich brauche es nicht, weil Arbeitsjob habe ich, mein Mann hat Job und andere brauch' ma eh nicht. " (Kroatin, 44 Jahre, nichteingebürgert)

R10: „Da müssen wir unsere rumänische Staatsbürgerschaft verlassen und 1500 Euro zahlen. Und da war für uns damals sehr, sehr viel Geld. Und das heißt, für meine Frau und mich das sind 3000 Euro und das war viel zu viel Geld. " (Rumäne, 39 Jahre, nichteingebürgert)

Die Erfahrungen auf dem Arbeitsmarkt entsprechen mitunter nicht den Erwartungen der Zuwanderer. Die Einbürgerung hat bei etlichen Migranten keine spürbaren Veränderungen hinsichtlich ihrer arbeits-, sozial- oder wohnungsrechtlichen Positionierung bewirkt:

R6: „... also egal, ob du bist jetzt mit Staatsbürgerschaft oder ohne Staatsbürgerschaft bist, du bist Ausländer. " (Syrer, 39 Jahre, eingebürgert) 
I.: „Hat sich irgendwas verändert durch die österreichische Staatsbürgerschaft“ R5: „Nein!“ I.: „,War alles in der Arbeit gleich geblieben?“ R5: „Alles, alle ... “ (Exjugoslawin, 55 Jahre, eingebürgert)

R11: „... es spielt doch auch eine große Rolle, so die Staatsbürgerschaft zu haben, aber mit der Wohnung, ich muss dazu sagen, also wirklich es hat überhaupt nichts genützt. " (Syrer, 44 Jahre, eingebürgert)

Vor allem für die erste Generation der Immigranten war mit der Einbürgerung auch eine Verbesserung der Wohnungsmarktpositionierung verbunden:

E.: „... man hat die Staatsbürgerschaft damals der erste Generation deshalb auch genommen, damit die Arbeitssituation halt erleichtert wird und natürlich auch die Zugang zu Wohnung. " (Expertin, Gebietsbetreuung, türkischer Migrationshintergrund)

Ein wichtiges Faktum ist, dass die Staatsbürgerschaft als Zugangsvoraussetzung zu Kommunalwohnungen in Wien mit 1. Jänner 2006 gefallen ist, denn etliche Befragte haben aus diesem Grund zuvor keine Gemeindewohnung erhalten Der Konnex der österreichischen Staatsbürgerschaft mit dem Zugang zu einer Gemeindewohnung wurde im Kontext des Abwägens der Gründe für die Einbürgerung auch verbalisiert. Der Zugang zu einer Kommunalwohnung war vor der Änderung der Gesetzeslage nicht selten die Ultima Ratio für oder wider die Einbürgerung:

R2: „In dieser Zeit ... hat nicht Recht Ausländer zum Gemeindewohnung kriegen. ... Gemeindewohnung hamma nicht gekriegt und Mietewohnung war teuer. " (Kroatin, 44 Jahre, nichteingebürgert)

R5: „...früher nix Gemeindewohnung, muss österreichische Staatsbürgerschaft ... und ich später österreichische Staatsbürgerschaft ... “ (Exjugoslawin, 55 Jahre, eingebürgert)

R4: „Ja, es war mir schon wichtig, dass Gemeindebau wohnen. ... Weil das ist billiger, meine Meinung nach. " (Bosnierin, 44 Jahre, nichteingebürgert)

E.: „, Wenn einer eine Gemeindewohnung bekommen hat, war wie ein, als ob diese Person von den Lotto einen Sechser gewonnen hätte. Das war, die Leute waren neugierig, wollten besuchen, wie schaut Gemeindebauwohnung aus und das waren natürlich auch Anreiz, ja. Man musste nicht Ablöse zahlen. ... bei den privaten Wohnungen die Immobilienmakler haben sehr viel ausgenützt einfach." (Expertin, Gebietsbetreuung, türkischer Migrationshintergrund)

Das Bestreben geht aber in die Richtung, dass sich die zweite Generation aufgrund damit verbundener Vorteile doch einbürgern lässt:

R2: „Na, also ich und mein Mann wir haben noch kroatische Staatsbürgerschaft. ... Ja, und die Kinder haben österreichische Staatsbürgerschaft genommen. " (Kroatin, 44 Jahre, nichteingebürgert) R4: ,,... unsere Kinder, die sind geboren da, sie gehen zur Schule da, wenn sie dann nachher, ich weiß nicht, Alter 15, können sie das bean- 